\title{
The potential role of dietary plant ingredients against mammary cancer: a comprehensive review
}

\author{
Amjad Hussain ${ }^{a, b, c}$, Marie-Lise Bourguet-Kondracki ${ }^{b}$, Farhad Hussainc, Abdur Rauf ${ }^{\mathrm{d}}$, Muhammad Ibrahim ${ }^{c}$, Muhammad Khalid ${ }^{\mathrm{e}}$, \\ Hidayat Hussain ${ }^{\mathrm{f}}$, Javid Hussain ${ }^{\mathrm{g}}$, Iftikhar Ali ${ }^{\mathrm{h}}$, Anees Ahmed Khalii', \\ Fahad A. Alhumaydhi ${ }^{\mathrm{j}}$, Muhammad Khan ${ }^{\mathrm{a}}$, Riaz Hussain ${ }^{\mathrm{a}}$, and Kannan R. R. Rengasamy ${ }^{\mathrm{k}, \mathrm{lm}}$
}

aDepartment of Chemistry, University of Okara, Okara, Pakistan; 'Laboratoire Molecules de Communication et Adaptation des Micro- organismes, UMR 7245 MNHN-CNRS, Museum National d'Histoire Naturelle, Paris, France; cDepartment of Applied Chemistry, Government College University, Faisalabad, Pakistan; dDepartment of Chemistry, University of Swabi, Swabi, Anbar, Khyber Pukhtanuk (KP), Pakistan; eDepartment of Chemistry, Khwaja Fareed University of Engineering \& Information Technology, Punjab, Pakistan; 'Department of Bioorganic Chemistry, Leibniz Institute of Plant Biochemistry, Halle (Salle), Germany; 9Department of Biological Sciences \& Chemistry, College of Arts and Sciences, University of Nizwa, Nizwa, Sultanate of Oman; hDepartment of Chemistry, Karakoram International University, Gilgit, Pakistan; iUniversity Institute of Diet and Nutritional Sciences, Faculty of Allied Health Sciences, The University of Lahore, Lahore, Pakistan; iDepartment of Medical Laboratories, College of Applied Medical Sciences, Qassim University, Buraydah, Saudi Arabia; knstitute of Research and Development, Duy Tan University, Da Nang, Vietnam; 'Faculty of Environment and Chemical Engineering, Duy Tan University, Da Nang, Vietnam; mIndigenous Knowledge Systems Centre, Faculty of Natural and Agricultural Sciences, North-West University, Mmabatho, South Africa

KEYWORDS

Breast cancer; chemoprevention; dietary supplements; functional foods; molecular mechanisms; phytochemicals

\begin{abstract}
Breast cancer is known as the most devastating cancer in the global female community and is considered as one of the severe health care burdens in both developed and developing countries. In many cases, breast cancer has shown resistance to chemotherapy, radiotherapy and hormonal therapy. Keeping in view these limitations, there is an urgent need to develop safe, readily available and effective breast anticancer treatments. Therefore, the scientists are keen in the extraction of plant-based phytochemicals (organosulfur compounds, betalains, capsaicinoids, terpenes, terpenoids, polyphenols, and flavonoids) and using them as breast anticancer agents. Results of numerous epidemiological investigations have revealed the promising role of phytochemicals in the prevention and treatment of breast cancer. The diverse classes of plant bioactive metabolites regulate different metabolic and molecular processes, which can delay the proliferation of cancers. These phytochemicals possess chemo-preventive properties as they down-regulate the expression of estrogen receptor- $a$, inhibit the proliferation of cancer cells, and cause cell cycle arrest by inducing apoptotic conditions in tumor cells. This review article discusses the potent role of various plant-based phytochemicals as potential therapeutic agents in the treatment or prevention of breast cancer along with the proposed mechanisms of action.
\end{abstract}

\section{Introduction}

Breast cancer is a disease associated with uncontrolled proliferation of cells in breast tissue. Majority of breast cancers forms lumps in lobules or ducts connecting lobules to the nipples (ACS 2019). Globally, breast cancer is known to be the second leading causes of death among women (Shareef, Ashraf, and Sarfraz 2016). Various factors, including gender, sedentary lifestyle, diet, alcohol consumption, age, family history, and several reproductive and hormonal factors, are thought to be the leading cause of breast cancer. Nevertheless, it is still unclear to identify any specific factor to be the most responsible in the pathogenesis of mammary cancer (Abdulkareem 2013). In 2012 it was considered as the second most common cancer with identification of 1.7 million new cases (Siegel, Naishadham, and Jemal 2012). In 2019, the National Cancer Institute estimated that one in eight women would produce mammary cancer in her life (Howlader et al. 2019). During January 2019, it was approximated that in the United States, more than 3.8 million women were alive who suffered mammary cancer in their past (ACS 2019). It is identified that mammary cancer is common in postmenopausal women rather than premeno- pausal. In South-East Asian women, the occurrence of breast cancer is low as compared to other women in Europe and America (Youn and Han 2020). The estimated figures for new cases and deaths in the United States are given in Table 1.

According to an estimate, nearly $12 \%$ of women could develop breast cancer during their life (Howlader et al. 2017). On the other hand, nearly $72 \%$ and $69 \%$ of women will develop breast cancer until the age of 80 who had inherited BRCA1 and BRCA2 mutations, respectively (Kuchenbaecker et al. 2017). BRCA1 and BRCA2 are two predominant human tumor suppressor genes that play an essential role in stabilizing the genetic material of cell by repairing the damaged DNA. Mutation or alteration of any of these genes results in impaired functionality of protein products hence resulting in improper repairing of damaged DNA. Therefore, normal cells are more prone to develop extra genetic alterations resulting in cancer. Women having inherited mutations in BRCA1 and BRCA2 genes have more chances of developing breast cancer compared with women having no inherited mutations of these genes (Friebel, Domchek, and Rebbeck 2014). Nearly 25\% of hereditary breast cancer is reported to be due to mutation in BRCAl and BRAC2 genes (Hawsawi et al. 2019). 


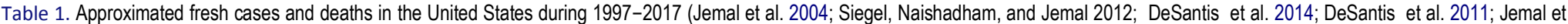
al. 2006; Jemal et al. 2008; Jemal et al. 2010; Jemal et al. 2009; Siegel et al. 2014).

\begin{tabular}{|c|c|c|c|c|c|c|}
\hline \multicolumn{4}{|c|}{ Approximated fresh cases } & \multicolumn{3}{|c|}{ Approximated deaths } \\
\hline Year & Both genders & Male & $\overline{\text { Female }}$ & Both genders & Male & Female \\
\hline 1997 & 181,600 & 1400 & 180,200 & 44,190 & 290 & 43,900 \\
\hline 1998 & 180,300 & 1600 & $1 / 8, / 00$ & 43,900 & 400 & 43,500 \\
\hline $19 y 9$ & $1 / 6,300$ & 1300 & $1 / 5,000$ & 43,100 & 400 & 43,300 \\
\hline 2000 & 184,200 & 1400 & 182,800 & 41,200 & 400 & 40,800 \\
\hline 2001 & 193,100 & 1500 & 192,200 & 40,600 & 400 & 40,200 \\
\hline 2002 & $2 U 5, U \cup U$ & 1500 & 2U3,5UU & 40,000 & 400 & $3 y, 6 \cup U$ \\
\hline 2003 & 212,600 & 1300 & $211,3 \cup 0$ & 40,200 & 400 & $3 y, 800$ \\
\hline 2004 & $21 /, 440$ & 1450 & $215, y 90$ & 40,580 & $4 / U$ & 40,110 \\
\hline 2005 & 212,930 & 1690 & 211,240 & $40,8 / 0$ & 460 & 40,410 \\
\hline 2006 & 214,640 & $1 / 20$ & 212,920 & 41,430 & 460 & $40,9 / 0$ \\
\hline 2001 & 180,510 & 2030 & $1 / 8,480$ & $40, y 10$ & 450 & $4 U, 46 U$ \\
\hline 2008 & 184,450 & 1990 & 182,460 & 40,930 & 450 & 40,480 \\
\hline $200 Y$ & 194,280 & 1910 & $1 y z, 3 / 0$ & 40,610 & 440 & $4 U, 1 / U$ \\
\hline 2010 & 209,260 & $19 / 0$ & 201,090 & 40,230 & 390 & 39,840 \\
\hline 2011 & 232,620 & 2140 & $230,, 480$ & $3 y, y / 0$ & 450 & 39,520 \\
\hline 2012 & 229,060 & 2190 & $226,8 / 0$ & $3 y, y 20$ & 410 & $3 y, 510$ \\
\hline 2013 & 234,580 & 2240 & 232,340 & 40,030 & 410 & 39,620 \\
\hline 2014 & 235,U3U & 2360 & $232,6 / 0$ & $4 U, 430$ & 430 & $4 U, U U U$ \\
\hline 2015 & 234,190 & 2350 & 231,840 & 40,130 & 440 & 40,290 \\
\hline 2016 & $24 y, \angle 6 U$ & 2600 & $246,66 \mathrm{U}$ & 40,890 & 440 & $4 U, 45 \mathrm{U}$ \\
\hline 2017 & 255,180 & 2470 & 252,710 & 41,070 & 460 & 40,610 \\
\hline
\end{tabular}

Currently, breast cancer is common in Pakistan and considered every ninth woman suffered, and prevalence is 2.5 times greater in Pakistan than other adjacent states like India and Iran (Asif et al. 2014). In Pakistan, the most com- mon cancer developing within Muslim women is mammary cancer. The Confirmation from Karachi cancer registry specifies that the age uniform yearly level of mammary cancer is 69.1 per 100,000, which is the comparable rate to North America as well as Europe (Bhurgri 2004). The evidence from Shaukat Khanum hospital Lahore, Pakistan indicates that in 8 years period, there were presented 3,338 new cases of mammary cancer (Badar et al. 2005). In 2006, the multiple cases of breast cancer in Pakistani families were found $42.8 \%$ and $11.9 \%$ of BRCA1 and BRCA2 mutations for solitary cases of mammary cancer (Rashid et al. 2006). Among four Asian (China, Pakistan, Thailand, India) countries, highest breast cancer incidence and mortality rates were noticed in Pakistan (Mubarik et al. 2019; Mubarik et al. 2020).

Nowadays, research is focused on the prevention and treatment of cancer. In this context, the emphasis is on fighting cancer by employing anticancer agents that are effective, economical, safe, and have least side effects. Various approaches practised nowadays include radiotherapy, chemotherapy, phototherapy, stem cell transformation, and surgery of tumor. These methods to treat cancer are often associated with severe side effects (Patra, Mukherjee, and Kotcherlakota 2014; Vinogradov and Wei 2012). Most of these side effects include vomiting, nausea, pain, fatigue, gastrointestinal problems, hair loss, and weight alterations (Pearce et al., 2017; Schirrmacher, 2019). Another limitation in the continual use of anticancer drugs is the resistance of cancer cells toward these drugs due to mutation. Hence, outcomes of various scientific investigations have revealed the potential of plant-based metabolites as potent anticancer agents owing to their effective and less toxic nature (Singh et al. 2016). In numerous countries, various medicinal plants (>3000) have been studied for their anticancer properties (Tariq et al. 2017; Alves-Silva et al. 2017). These phytochemicals (phenolic acids, flavonoids, terpenoids, polyphenols, etc.) are produced by different parts of plants such as leaves, flowers, roots, seeds, peels, fruits, and barks. These plant- derived anticancer agents have numerous health benefits by inducting antioxidative potential, activating DNA-repair mechanisms, and by suppressing cancer cell-activating proteins (Iqbal et al. 2017). This review is focusing on the chemo-preventive potential of plant-based phytochemicals, specifically against breast cancer.

\section{Symptoms}

At the early stage of breast cancer, symptoms are undetectable, that explains the importance of early screening, but these symptoms can occur quickly, nearly in weeks or months. The most frequently, a painless lump is developing. Changes in the size or shape of breast are less common signs but can occur, and breast can become heavy, swelled and painful. The skin of that breast happens to change, its color becomes reddish, or an orange peel appears, and the skin wrinkled or dimpled. The nipple becomes thickened and retracted (Sharma et al. 2010).

\section{Risk factors}

Certain lifestyle factors such as consumption of alcohol and fat-rich diet increase the incidence of breast cancer. Frequent consumption of alcohol increases the concentration of blood estrogen-related hormones and triggers the estrogen-receptor pathways. Alcohol consumption, even in small amount upgrades the risk of mammary cancer because it rises estrogen and androgen level (Singletary and Gapstur 2001). It was observed that the consumption of alcohol in women rises the possibility of mammary cancer, around $7 \%$ to $10 \%$ per approximately one drink in a day (Liu, Nguyen, and Colditz 2015). The women who have alcohol consump- tion of 2 to 3 drinks per day increase their risk factor of 20\% as compared to nondrinkers. Before first pregnancy alcohol consumption may also significantly affect the risk (Liu, Nguyen, and Colditz 2015). Long-term smoking is also associated with an increased risk of mammary cancer.

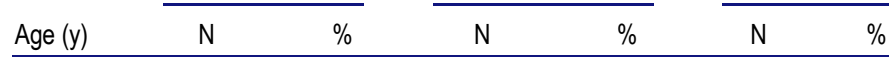




\begin{tabular}{lrrrrrr}
\hline$<40$ & 1180 & 2 & 11,870 & 4 & 1070 & 3 \\
$40-49$ & 8130 & $1 /$ & 31,150 & 14 & 3250 & $y$ \\
$50-59$ & 12,130 & 26 & 61,560 & 23 & 1460 & 18 \\
$60-69$ & 14,460 & 30 & 14,820 & 28 & 9920 & 24 \\
$70-79$ & $8 / 10$ & 18 & 52,810 & 20 & 890 & 21 \\
$80 p$ & 2830 & 6 & 30,390 & 11 & 11,150 & 27 \\
& 48,100 & & 268,600 & & 41,760 & \\
\hline In situ cases & & & & Invasive cases & Deaths
\end{tabular}

Total

NAT2 genetic polymorphism identified in smokers might confer an elevated risk of mammary cancer (Kispert and McHowat 2017). It has been reported that smoking addict women before their first pregnancy had a $21 \%$ more possibility to develop breast cancer than nonsmoker women (Gaudet et al. 2013). Radiation exposure is also a risk factor in increasing breast cancer, and this was studied during an atomic bomb attack in Japan. After the incident, survivors and females between 10 and 30 years of age were treated through high dosage radiations therapy to the chest (Preston et al. 2002). The breast cancer started to appear about eight years after treated with radiations (Travis et al. 2003).

Around the globe, main risk factors that relate to breast cancer could be characterized as demographic (age, gender), reproductive (age of first menstruations, age of menopause, full-term pregnancy, abortion, and pregnancy characteristics), hereditary (genetic and family history), hormonal (oral contraceptives and HRT-hormone replacement therapies), lifestyle (diet, obesity, alcohol consumption, smoking, and physical activity), and some other factors (air pollution, diabetes, and radiation). Among these, gender and age are major risk factors of breast cancer. This disease is mostly associated with female gender, and in males, the incidence of this cancer is very low (>1\%) as compared to other malignancies. Important risk factors of occurrence of breast cancer in old aged men may be any family history of breast cancer, hormonal imbalance, and mutation in human tumor suppressor gene (BRCA2) (Momenimovahed and Salehiniya 2019). Besides gender, the second leading risk factor for breast cancer is age. As the age increases, possibilities of breast cancer increase till the age of menopause, where the rate of breast cancer is maximum. After this age, there is a slight decrease in the rate of breast cancer and remains constant throughout the lifespan (Kim, Yoo, and Goodman 2015). In the United States, nearly $99 \%$ and $71 \%$ mortalities due to breast cancer were observed in women at an age above forty and sixty, respectively. The approximated new cases and deaths of the female by age due to breast cancer during 2019 are figured out in Table 2.

Among reproductive risk factors, younger age of first menstruations, first pregnancy in late age, and old age menopause are associated with increased risk of breast cancer. Risk of breast cancer decreased up to 5\% and 10\% with every one-year delay in age of menarche and multi-parity, respectively. At the same time, the risk of breast cancer increases by 3\% with every one-year delay in the age of menopause (Horn and Vatten 2017). Use of orally administrated contraceptive pills and estrogen hormone replacement therapies (HRT) in post-menopause are also reported to be linked with an elevated risk of breast cancer. Whereas, frequently exercising postmenopausal women in the age group of 50 to 79 years were reported to have reduced risk of breast cancer (Sun et al. 2017; Momenimovahed and Salehiniya 2019).

Mammary anticancer effects of dietary phytochemicals

Phytochemicals, from the Greek word "Phuton" meaning plants, are chemical compounds that are produced by plants. Phytochemicals are usually mixed up with phytonutrients. Whereas phytochemicals are chemical compounds which may be favorable or may be harmful to human health, phytonutrients are chemical compounds, which have a positive effect on human health. All phytonutrients are phytochemicals, but not all phytochemicals are phytonutrients. Phytochemicals can be highly toxic as illustrated with ricin, found in castor seeds, which is one of the highly toxic and potent phytochemical poisons in the world (Tiwari, Brunton, and Brennan 2013). However, all phytochemicals are not toxic and harmful (Endo et al. 1987). If phytochemicals are protective agents for the plants, various studies reported their protective activities in different Human diseases, especially in cancer prevention.

Additionally, the results of several studies have reported the inhibitory effect of anti-breast cancer plant metabolites on cell cycle phases (Figure 1). Resveratrol from grapes, genistein from soybean, and quercetin from onion are known to be used as mammary anticancer agents (Jang et al. 1997; Murakami, Ashida, and Terao 2008; Nakagawa et al. 2000). Thousands of dietary phytochemicals from fruits, vegetables, grains, leaves, stems, roots of different plants may be designed for handling different infections. In this review, we reported and discussed some chemical compounds, which are extracted from dietary plants and used as mammary anticancer agents displayed in Figure 2. Furthermore, the effect of plant phytochemicals on different mechanistic path- ways involved in modulation of breast cancer is shown in Figure 3.

Organosulfur compounds

Organosulfur compounds are the subclass of organic com- pounds which contain sulfur. They are present in both animals and plants sources. In plants, they are found in Allium species vegetables as well as in plants of Brassica and Eruca genera. They are reported as biologically active compounds (Goncharov et al. 2016), and some organosulfur dietary compounds are suggested to inhibit breast cancer.

Allicin (1) is an organosulfur compound belonging to the Alliaceae family, obtained from the underground stem of fresh garlic (Block 1985). It was shown to have very healthy and beneficial effects. Allicin would be able to prevent substantial progress in colon, breast and endometrial cancer cells along with many human fibroblast lines. These effects can be attributed to its ability to reduce the level of cellular glutathione transiently (Hirsch et al. 2000). Allicin was reported to inhibit TNF-alpha-induced VCAM-1 protein expression in human breast MCF-7 cancer cell line up to $10 \mathrm{ng} / \mathrm{mL}$, and to reduce tumor cell migration and invasion (Lee et al. 2015). 


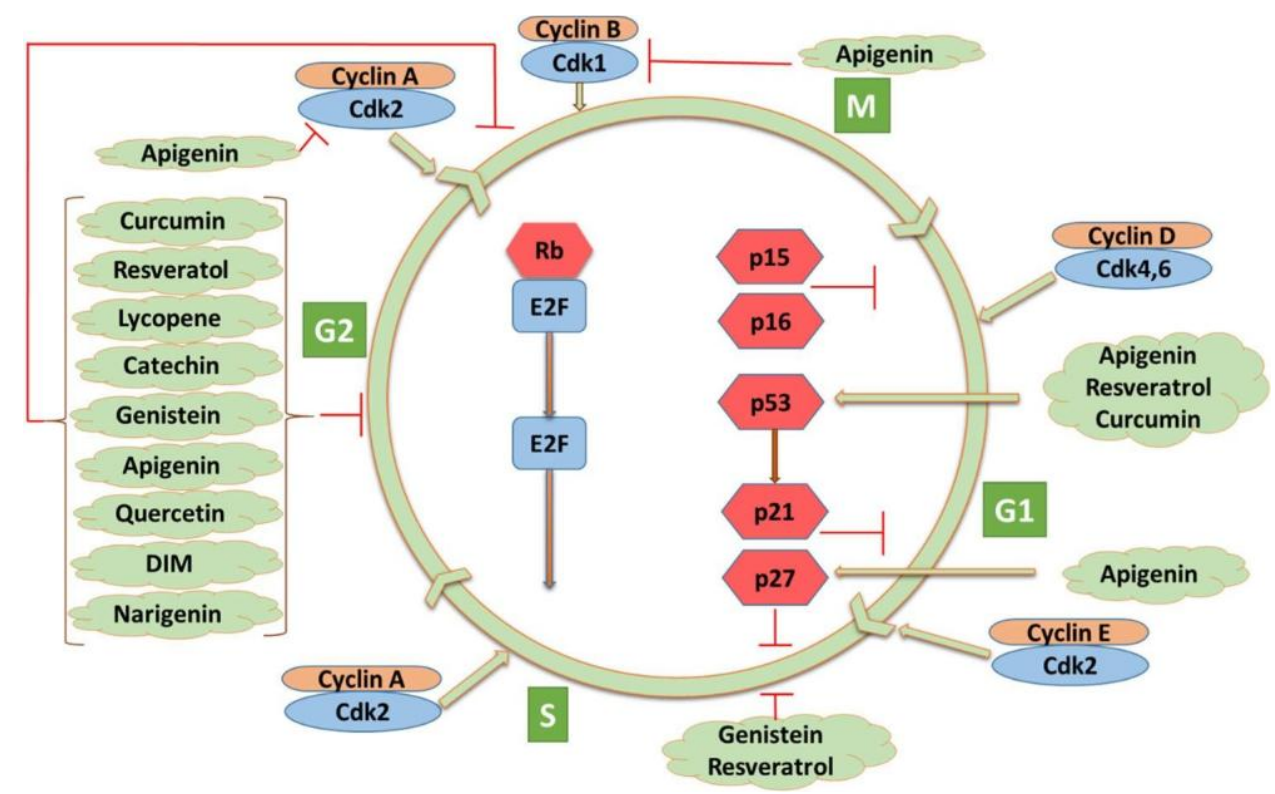

Figure 1. Inhibitory effects of anti-breast cancer plant metabolites on cell cycle phases.

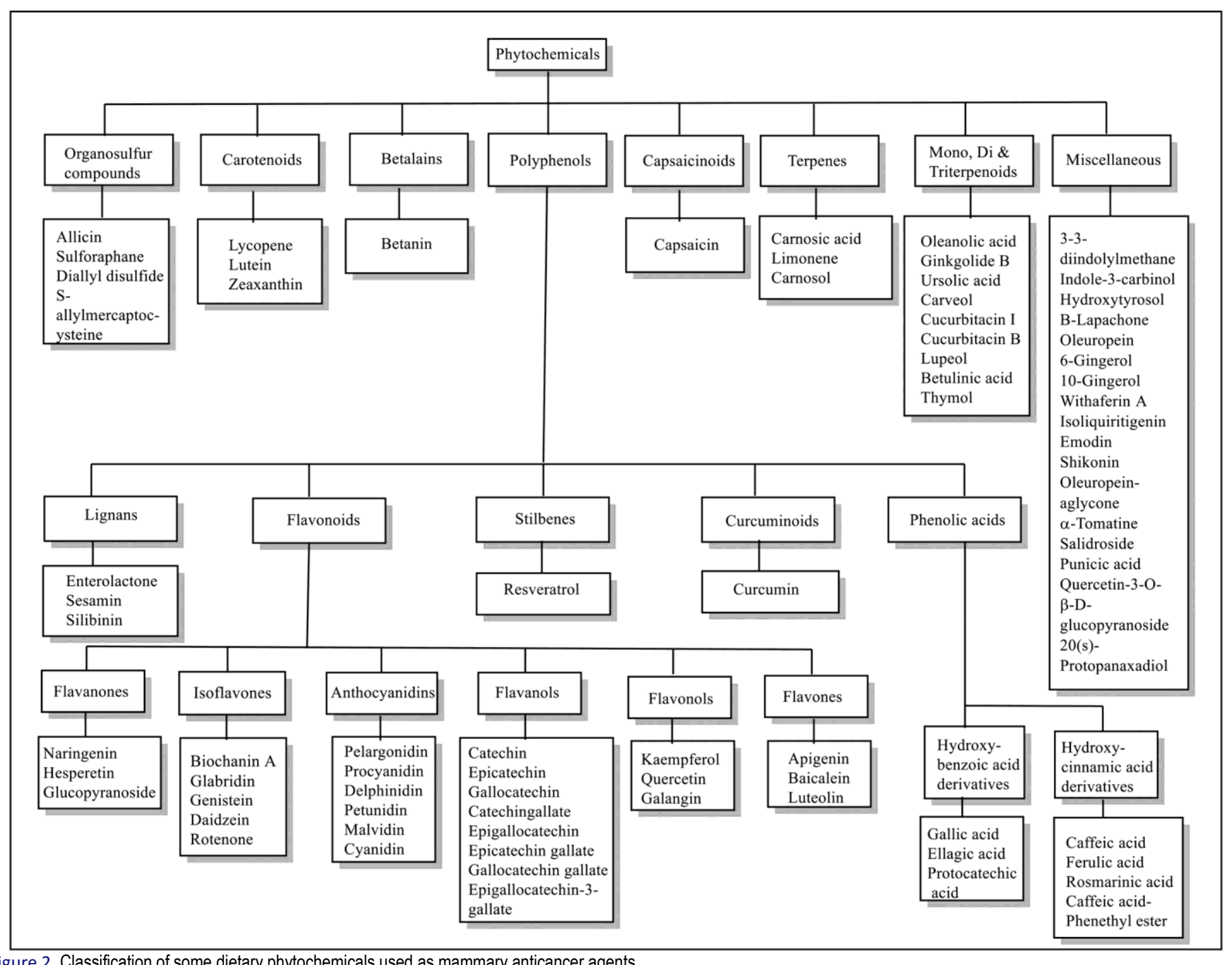

Figure 2. Classification of some dietary phytochemicals used as mammary anticancer agents. 


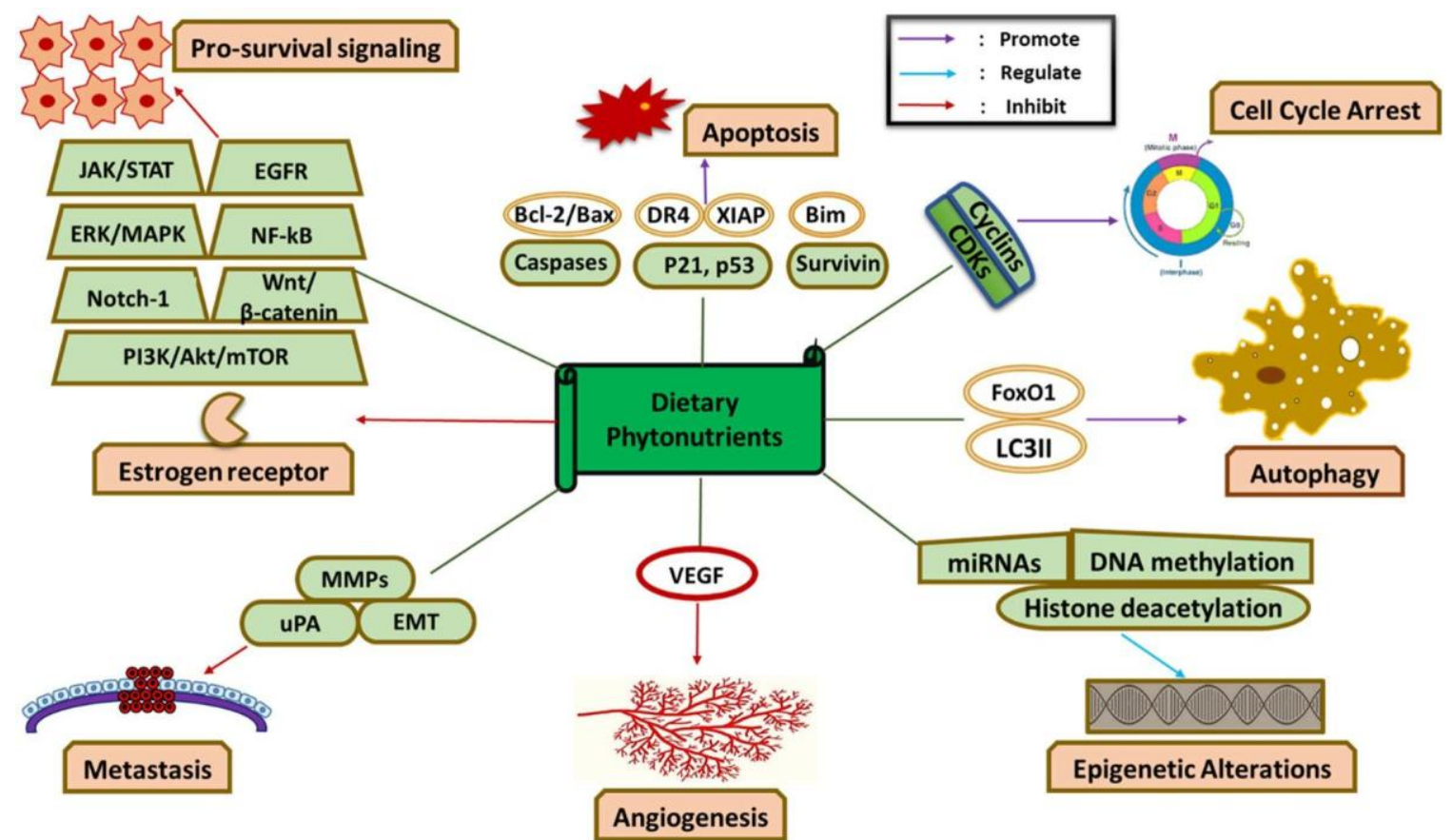

Figure 3. Effects of plant phytochemicals on different mechanistic pathways involved in modulation of breast cancer.

Sulforaphane (2) is an isothiocyanate derivative, present in broccoli and broccoli sprouts. It has been reported as being able to down-regulating WNt-beta catenin, one of the key pathways that promote self-renewal of breast cancer stem cells (Li et al. 2010). Accumulating studies provide support for the concept that breast carcinogenesis results from the deregulation of self-renewal pathways of normal mammary stem cells (Liu, Nguyen, and Colditz 2015) and might provide a novel approach for breast cancer treatment. Naturally occurring phytochemicals are known to be chemo- preventive metabolites having the potential to either delay, block or reverse the initiation and propagation of cancer. Sulforaphane is one of the most important phytochemical possessing anti-cancer perspectives. Purposely, Hussain and its coworkers reported the chemo-preventive potential of sulforaphane administration individually and in combination with gemcitabine (anti-cancer drug) on the proliferation of breast cancer cells (MCF-7) via modulating the expression of cyclooxygenase-2 (COX-2) and Bcl-2 in a time-dependent manner. The cytotoxic potential of sulforaphane would be due to apoptosis of breast cancer cells in a concentration - and time-dependent manner. The combined treatment of sulforaphane and gemcitabine synergistically caused a growth inhibitory effect on MCF-7 cells with a combination index of less than one. Therefore, the combined use of sulforaphane and gemcitabine not only could enhance the effectiveness of gemcitabine but also reduces toxicity in nor- mal cells (Hussain et al. 2013). Similarly, in vitro and in vivo investigations have revealed the potential of sulforaphane in suppressing the proliferation of triple-negative breast cancer cells (TNBCs). Sulforaphane inhibits the growth of cancer cells and retards the formation of cancer stem-like cells tumor sphere in TNBC (Castro et al. 2019).

Diallyl disulfide (DADS, 3) is a non-polar organosulfur compound soluble in oil and other non-polar solvents. It has been extracted from underground stems of garlic and also found in other plants of the Alliaceae family. DADS is responsible for strong garlic smell (Nakagawa et al. 2001). Various in vitro and in vivo models have been studied to assess the antitumor potential of diallyl disulfide. Purposely, Huang et al. (2015) reported that the effect of DADS reduced the viability, elevated apoptotic conditions, and sup-pressed the metastatic potential in examined TNBC line (in vitro). Moreover, DADS dysregulated Bcl-2, downregu- lated matrix metalloproteinase-9 (MMP-9) and reversed EMT (epithelialmesenchymal transition) via inhibition of the $b$-catenin signaling pathway. Further, in vivo indings also authenticated the anti-cancer perspectives of DADS in experimented MDA-MB-231 xenograft mice. Due to DADS treatment, a significant reduction in size and weight of tumor cells, along with the reduced expression of active $b$-catenin was noticed. Outcomes of this study suggested that the use of DADS might help prevent and treat breast cancer (Huang et al. 2015).

It was also reported that DADS significantly prevented

the development of human mammary cancer cells both in estrogen receptor (ER) positive (MCF-7 and KPL-1) and negative (MLK-F and MDAMB-231) in vitro and in vivo. Results of MTT-assay revealed $\mathrm{IC}_{50}$ of DADS ranging from1.8 to $18.1 \mathrm{M}$ post $72 \mathrm{~h}$ of incubation. In all four examined cell lines, treatment of DADS reduced the number of viable cells and induced cytotoxicity in a concentration - and time- dependent manner. Likewise, as compared to controls, treatment of DADS (1.8/M) in MDA-MB-231 cells resulted in apoptotic conditions due to Bax protein elevation

(142\%), 
Bcl-XL protein reduction (38\%), and caspase-3 up-regulation (438\%). DADS was reported to mitigate the cancer cell stimulatory effect of linoleic acid while the synergistic effect was observed when administrated with eicosapentaenoic acid (cancer cell suppressor) (Nakagawa et al. 2001).

S-allylmercaptocysteine (SAMC, 4) is an organosulfur compound, of aged garlic, also present in other Allium spe- cies vegetables. When tested on the proliferation and viabil- ity of diverse cancer cell lines, including erythroleukemia and hormone-dependant cancer cell lines, the two hormones of prostate and mammary responsible cancer cells clearly showed to be more sensitive to the growth-inhibitory influ- ence of thioallyl compounds. The anti-proliferative potential of stable thioallyl compound SAMC has been examined on hormone-responsive breast cancer (MCF-7) cell line. Treatment of SAMC at a dose of $>0.1 \mathrm{mM}$ has shown com- plete growth inhibition of MCF-7 cells, furthermore than $60 \%$ suppression was noticed at the SAMC dose of $0.05 \mathrm{mM}$ (Sigounas et al. 1997). Treatment of SAMC has effectively delayed cell growth, caused cell cycle arrest, and induced apoptotic conditions in MCF-7 (ER-positive) and MDA- MB-231 (ER-negative) cell lines. This potential of SAMC was mainly due to activation of caspase-3 and caspase-9, upregulation of p21, p53, and Bax, and downregulation of BCl-XL and Bcl-2 (Yi et al. 2019).

\section{Betalains}

Betalains are a group of red and yellow aromatic indole derivative pigments, frequently soluble in water. Most of these heteroside compounds have been isolated from plants of the order Caryophyllales, but are also present in Bougainvillea and some higher fungi such as Amanite (Baldassano et al. 2011). Betalains structures are close to flavonoids; their difference is that betalains react negatively to Erdmann test and migrate as anions even at a low PH of 2.4 (Piattelli, Minale, and Nicolaus 1965). Two categories of betalains are distinguishing according to the color of the pigment, namely betacyanins, which include the reddish to violet pigments and betaxanthins, which are yellow to orange pigments. Mostly betalains are used as coloring agents. Betanin (5) is the most abundant betacyanins pig- ment, mostly present in pokeberries and beetroots, isolated the first time in 1918 (Schudel 1918). Betanin contains nitrogen, which sets it apart from anthocyanins (Schudel 1918). It is reported that betanin acts against oxidative stress (Tesoriere et al. 2009) and that it can also significantly reduces the growth of several cancer cell lines such as breast, prostate (Kapadia et al. 2013) as well as colon, liver, skin cancer cells (Lechner et al. 2010). The 25 mM betanin dose was reported as an $\mathrm{IC}_{50}$ value against MCF-7 breast cancer cells. At low concentration, purified betanin and its isomer isobetanin revealed cytotoxic activity against tumor cells expressing functional p53 and very little or negligible effects against normal cells. In p53, wild-type tumor cells, betanin/ isobetanin extracts showed inducing apoptosis and autophagy. Moreover, betanin enriched extracts prevent some p53-mutated tumor cells development, without inducing apop tosis (Nowacki et al. 2015).

\section{Capsaicinoids}

Chili peppers contain the group of phytochemicals called capsaicinoids, which are responsible for the spiciness of the peppers (Tremblay, Arguin, and Panahi 2016). Capsaicinoids mostly contain homocapsaicin, nordihydrocapsaicin, dihydrocapsaicin and homodihydrocapsaicin. They are biologic- ally active compounds that showed acting as anticancer, anti-obesity, anti-inflammation and antioxidant agents (Luo, Peng, and Li 2011). Capsaicin (6), is a capsaicinoid, identified as being the alkaloid trans- 8-methyl- $N$-vanillyl-6-none- namide, a vanilloid receptor agonist. It constitutes the major pungent principle found in chili peppers of the Capsicum plants genus (Monsereenusorn et al. 1982). It prevents hun- ger, reduces in fullness and energy expenditure and fat oxi- dation (Tremblay, Arguin, and Panahi 2016) and has excellent growth-inhibitory effects against various tumor cells. It was demonstrated to be associated with cell-cycle arrest and apoptosis in the breast cancer cells. In vitro and in vivo investigations on breast cancer cells, including both ER-positive (BT-474, MCF-7, and T47D) and-negative (MDA-MB231, and SKBR-3) cancer cell lines, showed that capsaicin played an essential role as a novel moderator of EGFR/HER-2 pathway with a prospective starring role in the therapy and the blocking of the human mammary tumor (Thoennissen et al. 2010).

\section{Terpenes}

Terpenes are a diverse class of hydrocarbon molecules com- prising of isoprene units (5-carbons) and known as the largest type of plant secondary metabolites (Tidgewell, Clark, and Gerwick 2010). Two main representants, namely limonene and carnosic acid, are recognized as breast anticancer agents. Carnosic acid (7), a phenolic diterpene found in numerous Labiaceae plants, especially in leaves of the Mediterranean half-shrub rosemary, revealed anti-mammary tumor properties (Yesil-Celiktas et al. 2010). Alone or combined with curcumin, it may be useful to prevent and treat ER-negative breast cancer (Einbond et al. 2012). Furthermore, carnosol (8), the major oxidized metabolite of carnosic acid, which acts as an antioxidant agent, also showed anticancer activities (Lo et al. 2002) with $\mathrm{IC}_{50}$ values of $83 \mathrm{mM}$ at $24 \mathrm{~h}$ and $25 \mathrm{mM}$ at $48 \mathrm{~h}$ (Al Dhaheri et al. 2014). Further investigation on its mechanism of action revealed that it arrested at G2 phase of the cell cycle the development of invasive triple-negative MDA-MB-231 breast cancer cell line and induced ROS-dependent apoptosis as well as beclin1-independent autophagy (Al Dhaheri et al. 2014).

D-limonene (9), a monocyclic monoterpene, was found

in various fruits such as lemons, oranges, mandarins and grapes. Although it may use as flavor and also in perfumes, foods and soaps because of its pleasant smell (Sun 2007), it is also recognized as an anticancer agent in different types of cancers. Limonene showed acting as an antimammary agent during different phases of the cell cycle such as initiation, promotion and progression phases, also had chemo- therapeutic activities against rodent models with mammary malignancy (Crowell 1997). As it is well-tolerated, showing minimal toxicity in preclinical studies, it entered in phase-I of the clinical trials in patients with advanced cancer (Vigushin et al. 1998). A limited phase II evaluation followed this promising study in breast cancer.

\section{Terpenoids}

Terpenoids are modified terpenes, also derived from isoprene units, but most of them present multi-cyclic structures with oxygen containing functional groups. In plants, terpenoids play diverse functional roles such as hormones, structural components of membranes, electron carrier and photosynthetic pigments. Furthermore, they can be involved in communication and defense, as attractants for pollinators and seed dispersers, competitive phytotoxins, antibiotics, and herbivore repellents as well as toxins (McGarvey and Croteau 1995). They are also found in almost all living organisms; some of them being biologically active and recognized as able to fight against malaria, inflammation, cancers and other diseases (Mbaveng, Hamm, and Kuete 2014). 
photosynthetic bacteria, algae and plants. According to the presence or absence of oxygen in their structure, they are categorized into two classes: carotenes, which are oxygen-lacking carotenoids, as illustrated with beta-carotene, lycopene, and xanthophylls, which are the oxygenated carotenoids such as lutein, and zeaxanthin (Misawa 2010). Carotenoids give orange, red and yellow color to the plants but some red plants have no carotenoids. Around 40 to 50 of carotenoids of the human diet are provided by vegetables and fruits. The most common dietary carotenoids are alpha-, beta-carotenoids, lycopene and lutein. Some of them are recognized acting as breast anti- cancer agent, as illustrated with lycopene (10), a phytochemical carotenoid found in tomatoes, strawberries, cherries, papayas and carrots, but which has no provitamin-A function (Upadhyay 2018). However, it was evidenced that a large extent of lycopene reduces lungs, stomach, prostate, oral cavity, colon and mammary cancers with $\mathrm{IC}_{50}$ values in the range of 1-2 mM (Levy et al. 1995; Giovannucci 1999).

Additionally, lycopene revealed to inhibit insulin-like

growth factor-1-stimulated growth, which is autocrine / paracrine regulators of breast cancer cell growth. Hence, this action of lycopene might lead to new fronts in research focusing on the effect of lycopene treatment on regulation of endometrial cancer and other tumors. Lutein (11) is a xanthophyll family carotenoid, also recognized as anti-mammary agent. It is found in egg yolks, yellow carrots and vegetables of green leaves like kales and spinaches; this two latter having the highest amount of lutein. Its anti-mammary activity was investigated in female BALB/c mice, which were fed with $0.002 \%$ to $0.2 \%$ lutein. The results showed that the lowest volume of breast tumor had been observed with mice fed with $0.002 \%$ dietary lutein. Authors also indicated that at this dose, dietary lutein acted by selectively modulating apoptosis, and by inhibiting angiogenesis (Chew et al. 2003). Zeaxanthin (12), is a constitutional lutein isomer with, as the only difference, the location of a double bond in one of the ionone rings; each having a variety of different stereoisomers (Krinsky, Landrum, and Bone 2003). In the eye, lutein and zeaxanthin constitute macular pigments of the yellow region near the center of the retina, forming a very efficient filter for blue light, and high protection to healthy cells of eyes (Krinsky, Landrum, and Bone 2003).

\section{Triterpenoids}

Some triterpenoids, such as oleanolic acid (13) and its iso- merursolic acid (14), have been reported to possess mammary anticancerous properties. Both are pentacyclic triterpenoid compounds, present in a free acidic form in Nature, and widely spread in plants kingdom, especially in the species Olea europaea, Wrightia tomentosa, Rosa woodsii and Prosopis glandulosa. They revealed similar and diverse pharmaceutical activities such as anti-inflammatory, hepato- protective, anti-oxidant properties and anticancer effects (Jesus et al. 2015). Oleanolic acid, the active component of Wrightia tomentosa, showed inhibitory activity against MCF-7 and MDA-MB-231 mammary tumor cell lines with IC 50 values of 7.5 and $7 \mathrm{mg} / \mathrm{mL}$, respectively. This proliferation inhibition and the observed pro-apoptotic effects revealed to be due to induction of apoptosis pathway (Chakravarti et al. 2012). Ursolic acid is also present in many other plants such as basil, cranberries, blueberries, elderflowers, rosemary and others. Ursolic acid showed its ability to induce apoptosis and to modulate glucocorticoid receptor and activator protein1 in MCF-7 cells ( $\mathrm{IC}_{50}$ value of $0.4 \mathrm{mM}$ ) (Kassi et al. 2009).

Similarly, various plants of Cucurbitaceae family contain a diversified class of triterpenoids known as Cucurbitacins (Chen et al. 2005). It has been found that tyrosine-phosphorylated signal transducer and activator of transcription 3 (STAT3) has a vital role in human tumor malignancies. Cucurbitacin I (15) has reported suppressing the propagation of MDA-MB-468 (human breast carcinoma) cells line due to inhibition of phosphor-STAT3 and induction of apoptotic conditions (Blaskovich et al. 2003). Anticancer effect of Cucurbitacin B (16), another triterpenoid presents $\mathrm{s}$ in family Cucurbitaceae, has been studied against six different human cancer cell lines (MDA-MB-231, MCF-7, BT474, MDA-MB453, T47D, and ZR-75-1). Moreover, it showed that the proliferation of these human cancer cells suppressed because of the disruption of microtubules and F-actin (Wakimoto et al. 2008).

Lupeol (17) is a pentacyclic lupine-type triterpene (a phytosterol family, also named fagarsterol, clerodol, lupenol), mainly found in strawberries, green peppers, olives, white cabbages, grapes and mangos. Lupeol offers a broad spectrum of pharmaceutical activities, especially in anti- inflammatory diseases. In particular, lupeol showed reducing the prostaglandin E2 (PGE2) manufacturing in A23187- stimulated macrophages (Fernandez et al. 2001). It also showed anti-tumor activities against diverse cancers, including against MCF-7 breast cancer cell line, for which an $\mathrm{IC}_{50}$ value of $50 \mathrm{mM}$ was reported (Balapure and Wadegaonkar 2014). Lupeol stimulates the decoying effect of RA4 DNA sequence and in MDA-MB-231 ERa-negative mammary cancer cells was risen the level of ERa gene expression (Lambertini et al. 2005). A study on its mechanism of action was provided, showing its multi-target functionalities with a great anti-inflammatory potential targeting key molecular pathways which involve nuclear factor kappa B (NF/B), cFLIP phosphatidylinositol-3-kinase (PI3K)/Akt and Wnt/ b-catenin in a variety of cells (Saleem 2009). Due to its therapeutic effect at doses which exhibited no toxicity to normal cells and tissues, preclinical studies have been undergone in order to evaluate its chemopreventive activity, especially in cancers.

Betulinic acid (3b-hydroxy-lup-20(29)-en-28-oic acid)

(18) is a pentacyclic triterpene, extracted from birch trees. It revealed in vitro and in vivo potential anticancer effects, especially against breast cancers (Mertens-Talcott et al. 2013; Potze et al. 2014). Additionally, ionic derivatives of betulinic acid with water solubility improvement revealed higher cyto- toxicity against MCF-7 breast cancer cell line. Significantly, the derivative (19) showed an IC 50 value of 25 IM, which is around four-fold lower than that of betulinic acid (Suresh et al. 2012). Investigation of betulinic acid mechanism of action revealed a high complexity. Induction of apoptosis in cells p53 independent cells was shown. However, in very resistant triple-negative breast cancer cells (ER, progesterone receptor and HER2-negative), betulinic acid revealed to target Sp transcription factors. As Sp-specificity proteins are overexpressed in cancers and take part in the proliferation and angiogenic phenotype affiliated with tumor cancer cell lines, this result suggests a high potential of betulinic acid in clinical trials. Recent studies showed that it could attenuate migration and invasion of highly aggressive breast cancer cells via aerobic glycolysis inhibition. It also revealed a novel regulatory pathway between GRP78 and glycolytic metabolism in cancer cells (Zheng et al. 2019).

\section{Diterpenoids}

Ginkgolides are diterpenes comprising of twenty-carbon atom skeleton and are abundantly present in Ginkgo biloba tree. Investigations on ginkgolide B (20) from the fruits of Ginkgo biloba revealed that the expression and localization of peripheral-type benzodiazepine receptor (PBR) correlated with human breast cancer cell proliferation and aggressive phenotype expression. Studies showed that although it did not affect the proliferation of non-aggressive MCF-7 cell lines, ginkgolide B revealed inhibitory activity against the highly aggressive MDA-MB-231. This latter, in opposite to MCF-7 cells, are rich in peripheral-type benzodiazepine receptors (Papadopoulos et al. 2000). These results suggested that the modulation of PBR expression could be used to control tumor growth (Papadopoulos et al. 2000). It has been reported that treatment of MCF-7 cells with ginkgolide B resulted in apoptosis due to induction of ROS (reactive oxygen species) production and elevation in the intracellular content of nitric oxide (NO) as compared to the untreated control group (Chan 2007). 
$\mathrm{IC}_{50}$ values of 1.2 and $1.0 \mathrm{mM}$, respectively (Patel and Thakkar 2014). Thymol (22) is another monoterpene abundantly present in fruits of Trachyspermum ammi. Thymol has been reported possessing cytotoxic potential along with the effect on apoptotic gene expression in numerous malignancies. Thymol revealed anti- cancer properties against MCF-7 cell line with $\mathrm{IC}_{50}$ values as $54 \mathrm{mg} / \mathrm{mL}(48 \mathrm{~h})$ and $62(72 \mathrm{~h}) \mathrm{mg} / \mathrm{mL}$. It further induced apoptotic conditions in MCF-7 cells by affecting the p21 and p53 gene expression (Seresht et al. 2019).

\section{Polyphenols}

Polyphenols, with more than 10,000 compounds, represent a broad chemical class found in vegetables, fruits, cereals and some beverages (Lason and Leskiewicz 2013). In plants, they are involved in the UV protection and defense against pathogens. In Humans, they are recognized as having poten- tial health benefits, mainly due to their antioxidant properties. They provide significant protection against the development of diverse chronic pathologies including can- cer, but also diabetes, cardiovascular diseases and aging. A majority of various polyphenols has been reported acting as breast anticancer agents. Polyphenols are classified into four sub-classes, according to the number of phenol rings they contain in their structure: lignans, stilbenes, curcuminoids, phenolic acids, and flavonoids.

\section{Lignans}

Lignans are diphenolic compounds, found in fiber-rich plants such as vegetables, grains, nuts, seeds as well as different beverages (Yoder et al. 2015). Flax and sesame seeds, which provide enterolactone and sesamin, respectively, have been mainly studied. Both are known natural antioxidants with potential health efficacy, mostly as mammary anti-cancer agents, due to their structural similarity to 17 - $b$-estradiol, being able to act as estrogenic and antiestrogenic compounds.

Flaxseeds of genus Linum in the Linaceae family are a rich source secoisolariciresinol diglucoside (Kitts et al. 1999), which is converted by a consortium of intestinal bacteria into active mammalian lignans, namely enterodiol and enterolactone (Tour' e and Xueming 2010). Enterolactone

(23) showed an $\mathrm{IC}_{50}$ value of $82 \mathrm{mM}$ at $24 \mathrm{~h}$ against MCF-7 cell lines (Danbara et al. 2005). It showed reducing the growth of hormonesensitive breast cancer, and it was sug- gested to be ER-mediated due to observed lignan binding to ER (Saarinen et al. 2000). Sesamin (24) is the most abundant lignan found in sesame seeds. It was reported to arrest the growth in the G1 phase of the cell cycle of human MCF-7 cell lines. This growth inhibition activity was correlated with down-regulation of cyclin D1 protein expression, a proto-oncogene that is overexpressed in many human cancers, through activation of proteasome degradation of cyclin D1 protein (Yokota et al. 2007).

Silibinin (25), from milk thistle Silybum marianum L., is known as an hepatoprotective agent in traditional phytotherapy. It showed to induce apoptosis in human breast cancer MCF-7 cells by down-regulated the expression of the ER alpha (ERa) through up-regulation of caspase 6 (Zheng et al. 2015). Furthermore, in triple-negative mammary cancer cell line MDA-MB-231, its action revealed to be connected with Wnt/bcatenin signaling inhibitory activity by suppressing lipoprotein receptor-related protein-6 (LRP6) expression at the transcription level (Lu et al. 2012). LRP6 is an essential co-receptor for the $\mathrm{Wnt} / \mathrm{b}$ - catenin-signaling pathway, known for playing an important role in breast cancer development and progression. Silibinin also showed down-regulating the potent tumor promotor 12-O-tetradecanoyl phorbol-13-acetate-induced MMP-9 expression by controlling COX-2 expression in mammary cancer cells MCF-7 and MDA-MB231 (Kim et al. 2009). Furthermore, its synergistic effects, when it is combined with paclitaxel in both wild-type and drug-resistant MDA-MB-435 and MCF-7 breast cancer cells, were correlated with a significant increase in the level of the pro-apoptotic protein BAX and a significant decrease in the level of the anti-apoptotic proteins, Bcl2 and survivin. These results have proposed silibinin as a useful drug in breast cancers prevention and treatment (Molavi et al. 2017).

\section{Stilbenes}

The most known stilbene, 3, 5, $4^{0}$-trihydroxystilbene, is resveratrol (26), first discovered by Michio Takaoka, in the grapes of Veratrum grandiflorum (Takaoka 1940). Later, it was reported in 1977 by Langcake from grapevines leaves, as a phytoalexin, being produced in response to pathogen or environmental damages (Langcake and Pryce 1977). Although mainly present in the red grape peel, it is also found in blueberries, raspberries and peanuts. Cis- or trans-configuration of resveratrol can be found as well as their glycosylated forms (Le Corre et al. 2005). Resveratrol, in its trans-configuration, was reported as a breast anti-cancer agent. It showed an $\mathrm{IC}_{50}$ value of $25 \mathrm{mM}$ against $\mathrm{MCF}$-7 breast cancer cells stably transfected with CYP19 (MCF-7 aro) (Wang et al. 2006). Due to its structural similarity to the estrogen agent diethylstilbestrol, it is considered as a phytoestrogen, able to act as either estrogen agonist or antagonist agent. Such compounds have generated tremendous interest because of their potential use in hormone replacement therapy and cancer prevention. Estrogen, which is synthesized from cholesterol, is catalyzed at the final reaction by the enzyme named aromatase CYP19. Inhibitors of aromatase have been recently developed for their potential chemo-prevention and therapy activity. From 1997, resveratrol's inhibitory involvement in the different tumor events, namely initiation, promotion and progression was demonstrated in mice breast cancers, suggesting it's useful as a potential chemo-preventive agent in breast cancer (Jang et al. 1997). Later, the phytoestrogenic activity of resveratrol was demonstrated by its potential to bind and to initiate alphaand beta-ERs control transcription of estrogen- responsive target genes. Resveratrol revealed inhibitory activity against breast cancer cell growth in both ER-positive and -negative cell lines by an apoptotic mechanism (Nakagawa et al. 2001).

\section{Curcuminoids}

Curcuminoids are the yellow pigments found in turmeric, the rhizome of Curcuma longa L. of the Zingiberaceae family. Curcumin (27), the major compound extracted from turmeric rhizome, traditionally used in Indian culinary curries, is well known for its antioxidant and antiinflammatory properties (Maheshwari et al. 2006). It also revealed anticancer activities, especially toward human breast cancer, revealing to be more efficient against MCF-7 cell line than against the human mammary epithelial cells MCF-10A with IC 50 values of 29 and 55 mg/mL at $24 \mathrm{~h}$, respectively (Ramachandran et al. 2005). Its antiproliferative effects are estrogen-dependent in MCF-7 ER-positive cells. Additionally, its significant in vitro anti-invasive effects revealed not to be estrogen-dependent in the MDA-MB-231 ER-negative breast cancer cells (Shao et al. 2002). It showed to induce apoptosis in mammary cancer cells by its influence on numerous signaling pathways, suggesting its potential use for prevention and treatment of mammary cancer (Duvoix et al. 2005).

\section{Phenolic acids}

Phenolic acids are largely distributed in plants, vegetables and fruits. They play a significant role in the growing and reproduction, but their primary role is to protect damaged plants against pathogens (Sahelian 2018). They also showed remarkable potential against different types of diseases, including cancer. According to the number of phenolic cores in their structure, phenolic acids are classified into hydroxy- benzoic acids and hydroxy-cinnamic acids.

Hydroxy-benzoic acids. Hydroxy-benzoic acids such as gallic acid, ellagic acid and protocatechuic acid showed acting as mammary anticancer 
agents. Gallic acid (28) also known as 3, 4, 5-trihydroxybenzoic acid is found in different fruits, especially in gallnuts, and also in tea leaves. Its broad bio- logical activities include anti-inflammatory, antiallergic and anti-carcinogenic properties. Gallic acid is also studied for its antitumor effects, especially in reducing the growth of MCF-7 human breast cancer cell in a dose dependent-man- ner (Hsu et al. 2011). Authors explored its mechanisms of action, showing that it acted at the $\mathrm{G} 2 / \mathrm{M}$ phase, resulting in an increase of the kinase inhibitor proteins $\mathrm{p}^{\mathrm{Kip} 1}$ and $21^{\text {Cip } 1}$ by suppressing Skp2-mediated polyubiquitination.

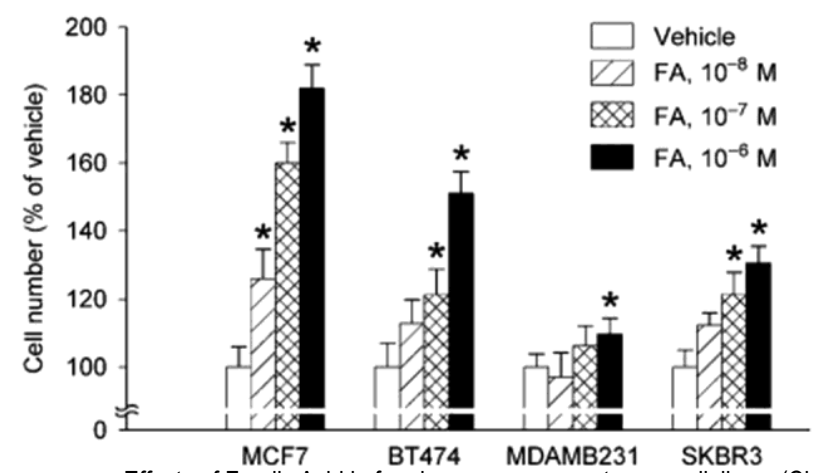

Figure 4. Effects of Ferulic Acid in four human mammary tumor cell lines (Chang et al. 2006). Reproduced with copyright permission from John Wiley and Sons.

Protocatechuic acid (29) also known as 3, 4-dihydroxy- benzoic acid is found in numerous medicinal plants, also in fruits, especially gooseberries, grapes and nuts. Protocatechuic acid showed to inhibit the proliferation of T47D breast cancer cell line, revealing a potent inhibitory activity with an $\mathrm{IC}_{50}$ value of $210^{-11} \mathrm{M}$ (Kampa et al. 2004). Ellagic acid (30) is a dimeric derivative of gallic acid, widely distributed in plants, red fruits such as grapes and pomegranates (Khalil et al. 2018; Khalil et al. 2017), berries including raspberries, strawberries, blackberries, cranberries, and some nuts such as pecans and walnuts. In plants, it is present in vacuoles as hydrolyzable, watersoluble ellagitannins, but can also be present in free form (Brat 2008). It was reported as an anticancer agent, suppressing MDA-MB-

231 breast cancer growth by inhibitikg angiogenesis. Exploring its mechanism of action revealed that it acted by suppressing VEGFR-2 tyrosine kinase activity, an essential target in the strategy of cancer therapy, with an $\mathrm{IC}_{50}$ of $\sim 25.8 \mathrm{nM}$ and by blocking its signaling pathway (Wang, Oo Khor, et al. 2012).

Hydroxy-cinnamic acids. Hydroxy-cinnamic acids are prenylpropanoids, present in different plants and seeds of fruits, vegetables and cereals and also in tea, cocoa, and wine. They are bio-synthesized through the shikimate pathway, starting from tyrosine or phenylalanine, the two precursor molecules of these class of compounds. These phenolic constituents revealed effective anti-inflammatory and antioxidant properties (El-Seedi et al. 2012). Caffeic acid and ferulic acid are the two hydroxy-cinnamic acids, which showed mammary anti-cancer properties.

Caffeic acid (31) or dihydroxy-cinnamic acid, naturally present in coffee, but also fruits, grains and vegetables, is known for its antioxidant, anti-proliferative and anti-inflammatory properties in normal cells (Kanimozhi and Prasad 2015). When tested against the proliferation of the hormone-sensitive T47D breast cancer cell line, it showed to be a potent inhibitor agent with an $\mathrm{IC}_{50}$ value of $2.17 \mathrm{nM}$ through pro-oxidant properties (Kampa et al. 2004). This activity revealed oxidative DNA damage and its downstream signaling induced apoptotic cancer cell death. Rosmarinic acid (32) is another caffeic acid ester, which was isolated from Salvia rosmarinus. It was reported that this compound prevented mammary cancer cell proliferation by minimizing COX-2 expression, antagonizing the extracellular signal- regulated protein kinase $1={ }_{2}($ ERK $1=2$ ) activation and AP-1 activation (Scheckel, Degner, and Romagnolo 2008). It was also reported that rosmarinic acid showed to abolish interleukin-8 in the pathway of the NF-jB and thus to hinder bone metastasis from mammary carcinoma (Wang, Wang, et al. 2012). One derivative, namely caffeic acid phenethyl ester (33), the active compound of the honeybee, showed to hinder NF-jB induced apoptosis via Fas signal activation in MCF-7 cell lines (Watabe et al. 2004). Another derivative, ferulic acid (34), found in leaves and seeds of different plants both in its free form and in covalently conjugated form, plays a broad role in the hardness of cell wall and synthesis of important organic constituents.

Ferulic acid is biologically active as antimicrobial, antioxidant, anti-allergic, hepatoprotective, anti-inflammatory, anti- carcinogenic and antithrombotic agent (Kumar and Pruthi 2014). It showed anticancer activity against different breast cancer cell lines, especially against MCF-7 cancer cell line, at a concentration of $10^{-6} \mathrm{M}$ presented in Figure 4 (Chang et al. 2006). The anti-proliferative activity of ferulic acid on T47D was reported with an $\mathrm{IC}_{50}$ value of $2.3 \mathrm{nM}$ (Kampa et al. 2004).

\section{Flavonoids}

Flavonoids constitute a broad family of benzo- $C$-pyrone derivatives with more than 6,000 identified compounds, so far; most of them in the free state but also as their respective glycosides. They are found ubiquitously in plants, producing yellow or red pigments for flower coloration, and in vegetables and fruits. They are also recognized as having pharmacological properties, due to their anti-oxidative, anti-inflammatory, antimutagenic and anti-carcinogenic reported properties (Kesarkar et al. 2009). Their activity showed to be associated with their chemical nature, their degree of hydroxylation, polymerization, conjugation, and substitution (Kumar and Pandey 2013). They are classified into different subclasses, namely flavanones, isoflavones, flavones, flavonols, flavanols, and anthocyanidins. Their synthesis was reported to follow the pathway of phenylpropanoids.

Flavanones. Flavanones are one of the main sub-classes of flavonoids, mainly found in Citrus plants (Rutaceae family). They are mostly present in fresh fruits, industrially processed or hand-squeezed Citrus juices, mostly obtained from sour oranges, limes, lemons, mandarins, grapefruits and tan- gors (Barreca et al. 2017). Naringenin and hesperetin are both major flavanones in their aglycone forms, which showed anti-cancer mammary activities. Naringenin (35) is one of the most important water-insoluble flavanone, obtained from the hydrolysis of its corresponding glycoside naringin (Orhan et al. 2015). The Naringenin and its glycosylated form (naringin) mostly found in Citrus species. Both, mostly found in grapefruits, are mainly known for their antioxidant activities. Accordingly, hesperetin (36) is the aglycone form of hesperidin. Both are mostly found in oranges (Roohbakhsh et al. 2014). Naringenin and hesperetin revealed inhibitory effects on growth and proliferation of human mammary tumor cell line MDA-MB-435 with an identical $\mathrm{IC}_{50}$ value of $18 \mathrm{mg} / \mathrm{mL}$. When tested in mixture, they showed an $\mathrm{IC}_{50}$ value of 22.5 $\mathrm{mg} / \mathrm{mL}$ (So et al. 1996). Hesperetin showed to block the proliferation and to arrest cell cycle at G1-phase in human breast cancer cells MCF-7, leading to apoptosis. Cyclins CDK4 and p21Cip1 have been suggested to be involved in the mechanism of action (E. J. Choi 2007). Quercetin$3-O-b$-D-glucopyrano- side (37) is one of the major constituents of apple peels, accounting for $82 \%$. It has been proven to be responsible for antioxidant effects and antiproliferative activity against breast cancer MCF-7 cell line, with an EC 50 value of $23.9 \pm 3.9$ mM (He and Liu 2008$)$. 
Isoflavones. Isoflavones are considered as phytoestrogens, being able to exert pseudo-hormonal activity by binding to ERs in mammalians. They revealed antioxidant, antimicrobial, anti-inflammatory activities, and they showed a significant role in the inhibition of hormone-related cancer such as breast cancers. Their benefits in the diet have been unveiled through studies showing that the ratio of breast and prostate cancer in Asian people was lower in comparison to those of Western people. These results were attributed to a higher presence of isoflavones in Asian diets (around 15-47 and 0.15-17 mg/day for Asian and Western diets, respectively) (Yu et al. 2016). Biochanin A, Glabridin, genistein, dadzein and rotenone are main isoflavones having mammary anti-cancer perspectives. Glabridin (38) is the main isoflavone present in Glycyrrhiza glabra licorice roots (Simmler, Pauli, and Chen 2013). Glabridin and their derivatives inhibited the growth of mammary cancer cell lines; the hydroxyl groups in glabridin playing a significant role in the proliferation-inducing activity and binding to the human ER.

Structure-activity relationships revealed that glabridin was three or four times more active, with an $\mathrm{IC}_{50}$ value of $5 \mathrm{mM}$ than its derivatives $2^{0}-O$-methylglabridin and $4^{0}-O$-methyl-glabridin (Tamir et al. 2000). Biochanin A (39), whose the primary sources are peanuts, red clovers and soya's (Yoon et al. 2012), revealed a wide range of biological activities, including antioxidant, anti-inflammatory, anti-carcinogenic and anticancer applications. It is reported to inhibit the mammary tumor growth in a xenograft model; showing a tumor size expressively smaller than in the control group at the dose of $15 \mathrm{mg} / \mathrm{kg}$ (Moon et al. 2008). Genistein (40) is found in soy, in the stem of fava beans (Kaufman et al. 1997). It showed to be an antioxidant agent, and to have weak estrogenic and antiestrogenic properties, to inhibit topoisomerase II and angiogenesis, and to induce cell differentiation. In vitro studies revealed that in the treatment with genistein, the expression of the epidermal growth factor (EGF) receptor mass was shortly up-regulated in mammary glands of immature rats. It could be due to the mechanism responsible for the increased cell proliferation seen at that age, which could prevent the development of mammary can- cer in adults. Authors speculate that Asian women are preserved of breast cancer because they have an early consumption of soy-derived foods containing genistein, confirming its essential benefits for the welfares of cancer chemo-protective activity (Lamartiniere 2000). Daidzein (41) is also an Isoflavone extracted from dried fruits, vegetables and nuts. However, Zante currants and raisins are considered the two wealthiest sources, which contain both genistein and daidzein. Both have estrogenic activity in Humans, acting as anticancer agents in human breast, prostate, bowels and other cancer cell lines (Liggins et al. 2000). However, although being structurally similar, they did not share the same mechanism of action. Genistein showed inhibitory cell proliferation with an $\mathrm{IC}_{50}$ value of $8.8 \mathrm{muM}$ in MDA-MB-468 cells, involving G2/M arrest and apoptosis (Balabhadrapathruni et al. 2000). The induced apoptosis in breast cancer cell lines MDA-MB-231 was associated with the inhibition of cyclin B1 and the induction of p21 (Choi et al. 1998). Daidzein induced inhibition growth of MCF-7 cells at a concentration greater than $25 \mathrm{mM}$ (Jin et al. 2010 ), leading to apoptosis through the mitochondrial caspase- dependent cell death pathway. Rotenone (42) is a natural pesticide isoflavone, mostly present in the seeds, stems, roots and leaves of Fabaceae plants. Rotenone was found highly active against MCF-7 breast cancer cell line, inducing apoptosis. This compound, involving ROS generation, showed to activate c-jun N-terminal kinase and p38 mitogen-activated protein kinases (p38 MAP) and to inactivate the ERK ${ }_{1=}$ (Deng, Huang, and Lin 2010).

Flavones. Flavones represent a subclass of flavonoids structurally related to the parent flavone 2-phenyl-1-benzopyran- 4-one. They have been proven to have a key role in plant adaption to the terrestrial environment, such as protection from UV radiations. Flavones revealed broad biological activities including antioxidant, anti-inflammatory, anti-microbial and anti-cancer activities (Jiang, Doseff, and Grotewold 2016). Three flavones members, namely apigenin, baicalein and luteolin, showed mammary anticancer activities. Apigenin (43) also known as $4{ }^{0}, 5$, 7-trihydroxyflavone, a secondary plant metabolite, present in some fruits such as grapefruits, oranges, and in vegetables including parsley, onions, wheat sprouts and also in tea, chamomile, as well as in red wine. Apigenin is found in natural sources in the form of apigenin-7-Oglucoside and various acylated derivatives but also as a dimer, named biapigenin, mostly in Hypericum perforatum buds and flowers (Shukla and Gupta 2010). Apigenin has wide biological applications. It plays a role in scavenging free radicals as antioxidant agent, anti- mutagenic, antiinflammatory, antiviral, anticancer and purgative activities (Salehi et al. 2019). It has a significant role in various cancers, including cervical, colon, hematologic, lungs, ovarian, prostate, skin, thyroid, endometrial, gastric, liver and breast cancers. Apigenin has been proven to have a significant role in inhibition MCF-7, T47D, MDA-MB231, MDA-MB-453 and MDA-MB-468 breast cancer cell lines proliferation (Shukla and Gupta 2010). However, its inhibitory effects revealed to be mediated by targeting different signal transduction pathway. In MCF-7and MDAMB-468 breast carcinoma cells, IC $_{50}$ values were determined as being 7.8 and $8.9 \mathrm{mg} / \mathrm{mL}$, respectively. However, although inhibition of ERK MAP kinase phosphorylation was recognized as a mechanism of action in MCF-7 cells, activation of ERK MAP kinase phosphorylation was observed in MDA-MB- 468 cancer cell line (Yin et al. 2001). Luteolin (44) is one of the most common flavonoids belong to this sub-class. It was reported in many plant families such as Apiaceae, Asteraceae, Gentianaceae, Lamiaceae, Ranunculacea, namely from Angelica keiskei, Apium graveolens, Petroselinum crispum, Cajanus cajan and several other plants. It showed antimicrobial, antioxidant, anticancer, activities (Lopez- Lazaro 2009). Luteolin has been proven suppressing the growth of MDA-MB-231 ER negative breast cancer tumor both in vitro and in vivo. Luteolin has proven to exert its antitumor activity through an inhibitory effect on epidermal growth factor receptor-mediated pathway (Lee, Oh, and Sung 2012). Baicalein (45) (5, 6, 7-trihydroxuflavone) is the aglycone form of baicalin; both being the main components found in Chinese traditional medicine plant Scutellaria bai- calensis Georgi (Lamiaceae family). Much attention has been given to both compounds due to their anti-inflammatory activities. They have been proven interested in food industries, cosmetics and pharmaceutical applications, including in cancers, mainly due to its protective effect against mitochondrial dysfunction (De Oliveira et al. 2015). Baicalein was also isolated from the Asian medicinal plant Oroxylum indicum. It is an isomer of genistein, which is recognized as the leading cancer chemopreventive flavonoid found in soy- derived foods. However, they revealed differential action on ER transactivation and apoptosis in MCF-7 breast cancer cells (Po et al. 2002). Genistein has been proven to exert a biphasic effect on the proliferation and death of MCF-7 cells, showing estrogenic activity to transactivate ERa at low concentrations. In opposite, baicalein did not display this biphasic effect and showed to inhibit E2-induced migration, adhesion and invasion through interfering with the G protein-coupled ER 30 (GPR30) signaling pathway (Shang et al. 2015).

Flavonols. Flavonols are one of the wide sub-class of flavonoids, having the common skeleton of 15 carbon atoms arranged in three rings. They are mostly present in fruits and vegetables such as apples, red grapefruits, sweet cherries, beans, broccoli, pear, onion, white currants and others (Harnly et al. 2006). They have wide biological activities, and three of them, namely kaempferol, quercetin and galangin, displayed mammary anti-cancer activities. Kaempferol (46) is found in beans, kales, chives, onions and apples (Bhagwat, Haytowitz, and Holden 2014). The effect of kaempferol was examined in MDA-MB-453 human mammary tumor cells and revealed that after treated with $50 \mathrm{mM}$ of kaempferol for $24 \mathrm{~h}$, apoptosis was induced via modulation of the p53 path- way (Choi and Ahn 2008). Kaempferol, having both estrogenic and antiestrogenic activity, showed a biphasic response on the estrogen activity, depending on $\mathrm{E}_{2}$ concentration. It has been proven stopping the focus formation induced by $\mathrm{E}_{2}$, to block the malignant transformation, which is caused by estrogens. It might regulate the level of estrogenic activity in the body and have potent effects in blocking estrogens disparity diseases (Oh, Kim, and Chung 2006). Quercetin (47) is mainly present in onions, cranberries, apples and pears (Bhagwat, Haytowitz, and Holden 2014). Quercetin revealed to hinder cell proliferation of MDA-MB-468 breast carcinoma cells with an $\mathrm{IC}_{50}$ value of $7 \mathrm{mg} / \mathrm{mL}$ and activity being some- what specific for p53 (Avila et al. 1994). It was reported that quercetin inhibited the growth of MCF-7 human breast can- cer cell line through two different mechanisms, by blocking cell cycle development through transient M phase accumulation and then G2 arrest of the cell cycle, and by inducing apoptosis (Choi et al. 2001). Galangin (48) is found in high 
concentrations in Alpinia officinarum roots, used as a spice and as a well-known medicinal herb in Asia. It showed to hinder the proliferation of MCF-7 breast carcinoma cells at two levels, by direct inhibition of CYP1A1 enzyme activity and by hindering CYP1A1 transcription caused by AhR ligands (Ciolino and Yeh 1999).

Flavanols. Flavanols are a sub-class of flavonoids, which possess flavan-3-ol core, that is mostly found in green teas, especially in the green tea plant Camellia sinensis, but also in cocoa beans as well as in diverse fruits such as apples, peaches, grapefruits, bananas, blackberries, strawberries, red currants (De Pascual-Teresa, Moreno, and Garc' 1a-Viguera 2010). Flavanols in their monomer form are called catechins and due to their two chiral carbons, exist as four diastereoisomers for each compound. Catechin (49) is the simplest flavan-3-ol, found commonly in different fruits such as apples, grape seeds and strawberries and red wine, green tea. Its broad biological properties include antioxidative, antihypertensive, anti-inflammatory, anti-proliferative, anti- thrombogenic, anti-hyperlipidemic activities (Zanwar et al. 2013). Epigallocatechin (50) is a flavanol with an inhibitory effect against MDA-MB231 breast cancer cell line. Epicatechin (51) is odorless white color ingredient mostly present in grapes, cocoa powder, green and black tea. It is a potent antioxidant agent (Bonetti, Brombo, and Zuliani 2017). Gallocatechin (52), Catechingallate (53), Gallocatechin gallate (54) and Epicatechin gallate (55) are compounds that belong to this group that showed to sup- press MDA-MB231 breast cancer cell line. The most abundant catechin is ( ) epigallocatechin-3-gallate (EGCG) (56), accounted for 50 to 80\% of green tea. EGCG is known for its potent antioxidant activity as well as anti-inflammatory and immunomodulatory properties. It has been proven to inhibit cell proliferation by decreasing the tumor vessel density in different cancer cell lines and breast cancer-xenograft models (Sartippour et al. 2001). Much attention has been paid to angiogenesis inhibitory activity since EGCG showed targeting specifically tumor angiogenesis and not normal tissues (Nagle, Ferreira, and Zhou 2006). Epigallocatechin-3-gallate is a major component of green tea. This compound has many biological activities, mainly as an antioxidant and anticancer agent. It also upgrades cardio- vascular health and weight loss and secures the skin damage from radiations (Nagle, Ferreira, and Zhou 2006). In breast cancer, EGCG showed to potentiate radiotherapy efficacy (Gu et al. 2013; Sartippour et al. 2001; Zhang et al. 2012) and has been proposed as an adjuvant in cancer therapy (Yiannakopoulou 2014). Its anticancer effects have proven to be mediated by blocking HIF-1a and NFjB pathways.

Anthocyanidins. Anthocyanidins are the aglycone forms of anthocyanins. They are colored water-soluble pigments, pre- sent in fruits and vegetables, which are responsible for colors in diverse seeds, fruits, leaves, flowers. They are famous for their antioxidant activities, and they display antimicrobial, anti-inflammatory activities (Khoo et al. 2017). According to the different substituents on the flavylium-B ring, the most common anthocyanidins are pentameric pro- cyanidin (57), pelargonidin (58), delphinidin (59), petunidin

(60), malvidin (61) and cyanidin (62). The most efficient anthocyanidin is malvidin, which showed an inhibitory effect of MCF-7 cell growth of $74.7 \%$ at $200 \mathrm{mg} / \mathrm{mL}$, reveal- ing an $\mathrm{IC}_{50}$ value of $32.2 \mathrm{mM}$ (Zhang, Vareed, and Nair 2005). Procyanidins are condensed flavanan-3-ols compounds, formed from ( ) epicatechin and ( ) catechin. They are mostly present in apples, grape seeds and grape skins, cinnamon, cocoa beans and chocolate. They are famous for their potential health benefits, especially in preventing coronary and heart diseases (Hammerstone, Lazarus, and Schmitz 2000), pentameric procyanidin, isolated from Theobroma cacao, was investigated against diverse human breast cancer cell lines, including MDA-MB-231, MDA-MB- 436, MDA-MB-468, SKBR-3 and MCF-7 cells. Interestingly, it was observed that pentameric procyanidin inhibited the growth of all these breast cancer cells. Furthermore, a selective activity was observed against the se human breast cancer cell lines as normal human mammary epithelial cells (MCF-10) remained resistant to this anthocyanin (Ramljak et al. 2005).

Miscellaneous compounds

The steroid sapogenin 20(S)-protopanaxadiol (63), also named 20(S)-PP and present in Panax ginseng and Panax pseudoginseng showed inhibitory activity against ERs in human mammary cancer MCF-7 cell lines both in vitro and in vivo. It was suggested that $20(S)$-PP inhibited cell proliferation with an $\mathrm{IC}_{50}$ value of $26.3 \mathrm{mM}$ and estrogen-stimulated gene expression in mammary cancer cells (Yu et al. 2007). More recently, it was shown that its potential mechanism might be attributed to the phosphatidylinositol 3-kinase/ Protein kinase B/Mammalian (PI3K/AKT/mTOR) signal pathway, mediating apoptosis of human breast cancer MCF-7 cells (Zhang et al. 2018). Compounds, changing $\mathrm{PI} 3 \mathrm{~K} / \mathrm{AKT} / \mathrm{mTOR}$ signaling pathway, have attracted great attention to scientists as they selectively target tumor cells, especially breast cancer cells, leaving normal tissues alive. Currently, a Chinese medicine named the "Yijinsheng Capsule," developed from 20(S)-PPD, is in phase 3 of clinical trials as radiotherapy and chemotherapy assisting agent. Indole-3-carbinole (I3C, 64) is a compound formed from glucobrassicin mostly present in vegetables like broccoli, Brussels sprouts, cabbages, cauliflowers and kales. It was studied that I3C inhibited tumor growth in breast, liver, lungs and cervix (Weng et al. 2008). I3C was investigated on both estrogen-dependent MCF-7 and estrogen non- dependent MDA-MB-231 breast cancer cell lines, and it showed inhibiting the growth of MCF-7 significantly with the induction of P-450 system, but a minimal effect was observed against MDA-MB-231 (Tiwari et al. 1994). The $33^{0}$-Diindolylmethane (DIM, 65) is a stable condensation product of indole-3-carbinol (I3C). Both compounds are found in Brassica vegetables (Le et al. 2003). DIM is reported as a chemo-preventing agent against various types of cancers, especially against human breast cancers. It has shown to inhibit the breast cancer cells growth in vitro and in vivo via induction of cell cycle arrest in G2/M phase. Studies on both estrogen-dependent MCF-7 cell line and on the more aggressive estrogen-independent MDA-MB-468 cell lines revealed different mechanisms of action. Treatment of MCF-7 cells with DIM, (60 mM) led to down-regulation of Cdc25A, which was mediated by an enhanced expression of miR-21. However, no change in miR-21 expression was observed in the ER-negative MDA-MB-468 breast cancer cell lines (Jin 2011). Hydroxytyrosol or dihydroxyphenylethanol (66) is the phytochemical mostly present in fruit and leaf of the olive tree (Olea europeae L). Its concentration in olive oil depends on the variety and maturation of olives. The healthy benefits of olive oil are worldly recognized through the famous traditional Mediterranean diet. Main biological activities of hydroxytyrosol are due to the strong antioxidant and anti-inflammatory properties, being able to act as a chemoprotective agent in cardiovascular diseases, cancers, and several other diseases including HIV (Vilaplana-P' erez et al. 2014). Hydroxytyrosol is considered as the most powerful antioxidant agent with an oxygen rad-ical absorbance capacity value of 68,576 , which is 15 times higher than that of green tea and 3 times higher than that of Coenzyme Q10 (Richards 2019). Oleuropein (67) is another compound extracted from olive fruits, its concentration was reported up to $140 \mathrm{mg} / \mathrm{g}$ olives, but the amounts decrease as the fruits ripen. It is responsible for the bitter taste of olives. Oleuropein has wide biological activities such as it act as antioxidant, anti-inflammatory, anti-cancer, anti-microbial, anti-viral and antiatherogenic agent (Haris Omar 2010). Hydroxytyrosol and oleuropein showed cell proliferation inhibition at the dose of 50 and $200 \mathrm{mg} / \mathrm{mL}$, respectively. Both induced cell apoptosis in estrogen-dependent MCF-7 breast cancer cells (Han et al. 2009). Oleuropein aglycone (68) revealed to induce apoptose in breast cancer cells, showing a 2-fold apoptotic effect in MCF- overexpress- ing HER2- than in MCF-7 cells, and highlighting the pivotal role of the proto-oncogene HER2 in protective effects and progression of human breast cancer (Menendez et al. 2007). 6Gingerol (69) is the predominant compound responsible for the pungent taste of ginger rhizome (Zingiber officinale Rosc.). It is worldwide used for its spicy and flavoring properties in numerous dishes and beverages. In addition to antioxidant activities, it revealed anti-inflammatory, antidiabetic and anti-cancer effects (Mashhadi et al. 2013). Its potential benefit for the prevention of breast cancer was studied, and 


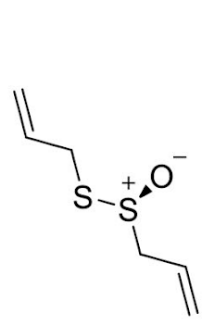

1

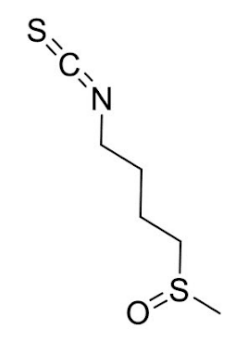

2

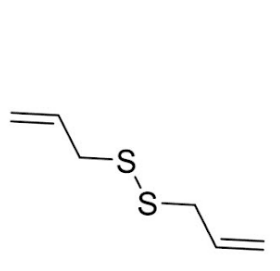

3<smiles>C=CCSC[C@H](N)C(=O)O</smiles>

4<smiles></smiles><smiles>CC(C)/C=C\CCCC(=O)NCc1ccc(O)c(CO)c1</smiles>

6<smiles>CC(C)c1cc2c(c(O)c1O)[C@@]1(O)CCCC(C)[C@H]1CC2</smiles><smiles>CC=C(C)CCCC(C)=CC=CC(C)=CC=CC(C)=CC=CC=C(C)C=CC=C(C)C=CC=C(C)CCC=C(C)C</smiles>

10<smiles>C=C(C)C1CC=C(C)CC1</smiles>

8<smiles>CC(C)c1cc2c(c(O)c1O)C13CCCC(C)(C)[C@@H](CCC2O1)C3=O</smiles>

9<smiles>CC1=CC(O)CC(C)(C)C1/C=C/C(C)=C/C=C/C(C)=C/C=C/C=C(C)/C=C/C=C(C)/C=C/C1=C(C)C[C@@H](O)CC1(C)C</smiles>

11<smiles>CC1=C(/C=C/C(C)=C/C=C/C(C)=C/C=C/C=C(C)/C=C/C=C(C)/C=C/C2=C(C)C[C@@H](O)CC2(C)C)C(C)(C)C[C@H](O)C1</smiles>

13

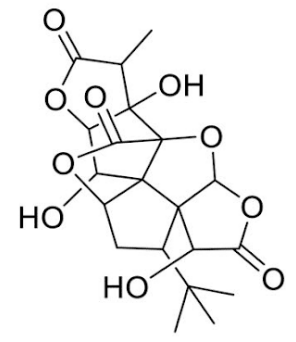

14

Figure 5. Chemical structures of dietary plants compounds showing mammary anticancer effects. 


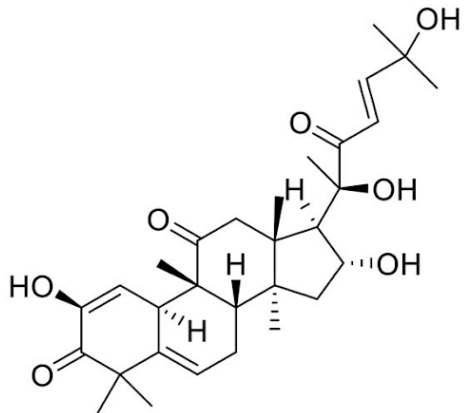

15

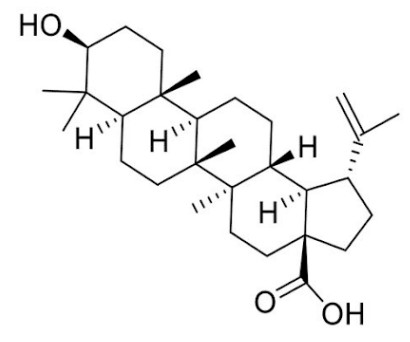

18

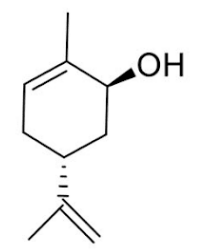

21

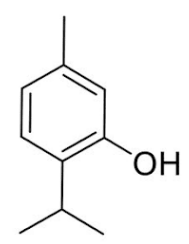

22

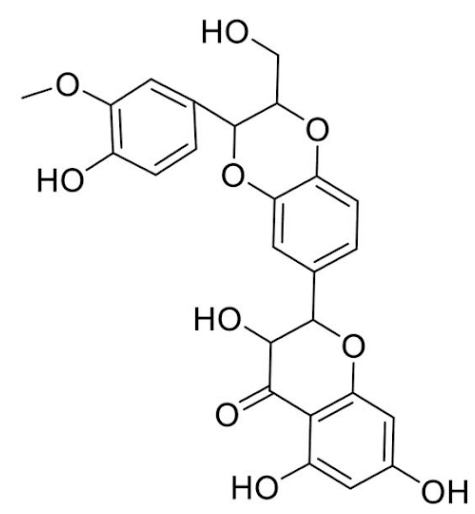

25

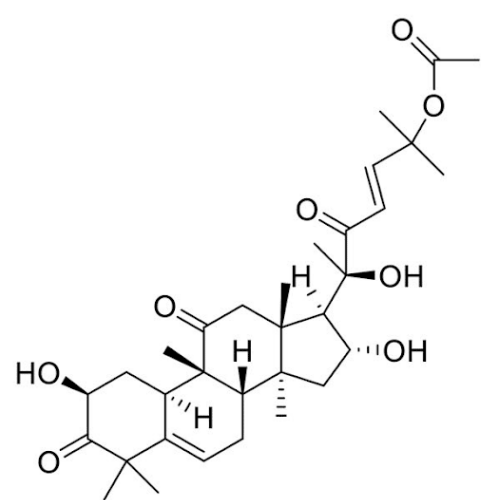

16

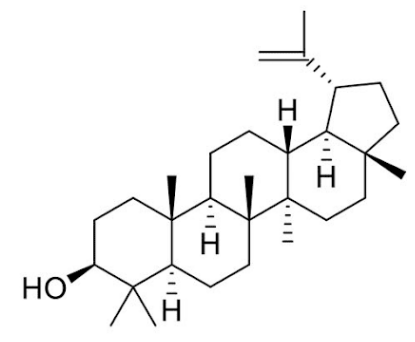

17

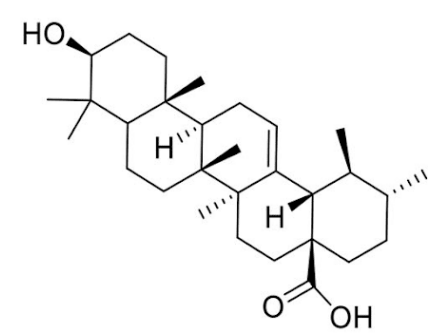

20<smiles>c1cc2c(cc1[C@H]1OC[C@H]3[C@H]1CO[C@H]3c1ccc3c(c1)OCO3)OCO2</smiles>

23<smiles>COc1cc(/C=C/C(=O)CC(=O)/C=C/c2ccc(O)c(OC)c2)ccc1O</smiles>

27
26<smiles>Oc1ccc(/C=C/c2cc(O)cc(O)c2)cc1</smiles> 
<smiles>O=C(O)c1cc(O)c(O)c(O)c1</smiles>

28<smiles>O=C(/C=C/c1ccc(O)c(O)c1)OC(Cc1ccc(O)c(O)c1)C(=O)O</smiles>

32<smiles>COc1ccc([C@@H]2CC(=O)c3c(O)cc(O)cc3O2)cc1O</smiles>

36<smiles>COc1ccc(-c2coc3cc(O)cc(O)c3c2=O)cc1</smiles>

39<smiles>O=C(O)c1ccc(O)c(O)c1</smiles>

29<smiles>O=C(/C=C/c1ccc(O)c(O)c1)OCCc1ccccc1</smiles>

33<smiles>O=c1c(OC2OC(CO)[C@@H](O)[C@H](O)[C@H]2O)c(-c2ccc(O)c(O)c2)oc2cc(O)cc(O)c12</smiles>

37<smiles>COc1cc(/C=C/C(=O)O)ccc1O</smiles>

34<smiles>CC1(C)C=Cc2c(ccc3c2OC[C@H](c2ccc(O)cc2O)C3)O1</smiles>

38

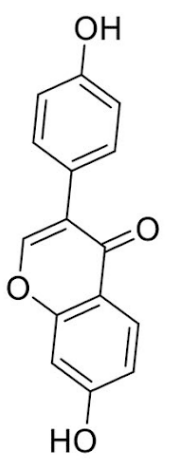

41<smiles>O=C1C[C@H](c2ccc(O)cc2)Oc2cc(O)cc(O)c21</smiles>

35

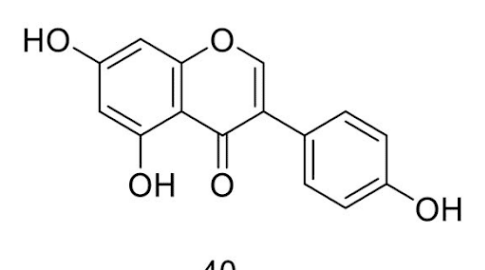

40<smiles>C=C(C)C1Cc2c(ccc3c2OC2CCc4cc(OC)c(OC)cc4C2C3=O)O1</smiles>

Figure 5. Continued. 
<smiles>[R]c1cc(-c2cc(=O)c3c(O)cc(O)cc3o2)ccc1O</smiles><smiles>[R]c1cc([C@H]2Oc3cc(O)cc(O)c3C[C@H]2O)cc(O)c1O</smiles>

$49 \mathrm{R}=\mathrm{H}$

$50 \mathrm{R}=\mathrm{OH}$<smiles>O=c1cc(-c2ccccc2)oc2cc(O)c(O)c(O)c12</smiles>

45<smiles>[R]c1ccc(-c2oc3cc(O)cc(O)c3c(=O)c2O)cc1[R]</smiles>

$46 \mathrm{R} 1=\mathrm{H}, \quad \mathrm{R} 2=\mathrm{OH}$

$47 \mathrm{R} 1=\mathrm{OH}, \mathrm{R} 2=\mathrm{OH}$

$48 \mathrm{R} 1=\mathrm{H}, \quad \mathrm{R} 2=\mathrm{H}$<smiles>[R]c1cc([C@H]2Oc3cc(O)cc(O)c3C[C@H]2O)cc(O)c1O</smiles>

$51 \mathrm{R}=\mathrm{H}$

$52 \mathrm{R}=\mathrm{OH}$<smiles>[R]c1cc([C@@H]2Oc3cc(O)cc(O)c3C[C@H]2OC(=O)c2cc(O)c(O)c(O)c2)cc(O)c1O</smiles>

$53 \mathrm{R}=\mathrm{H}$

$54 \mathrm{R}=\mathrm{OH}$<smiles>[R]c1cc([C@H]2Oc3cc(O)cc(O)c3C[C@H]2OC(=O)c2cc(O)c(O)c(O)c2)cc(O)c1O</smiles>

$55 \mathrm{R}=\mathrm{H}$

$56 \mathrm{R}=\mathrm{OH}$<smiles>Oc1cc(O)c2c(c1)O[C@H](c1cc(O)c(O)c(O)c1)[C@H](O)[C@H]2c1c(O)cc(O)c2c1O[C@H](c1cc(O)c(O)c(O)c1)[C@H](O)[C@H]2c1c(O)cc(O)c2c1O[C@H](c1cc(O)c(O)c(O)c1)[C@H](O)C2c1c(O)cc(O)c2c1O[C@H](c1cc(O)c(O)c(O)c1)[C@H](O)[C@H]2c1c(O)cc(O)c2c1O[C@H](c1cc(O)c(O)c(O)c1)[C@H](O)C2</smiles>

57<smiles>[R]c1cc(C2=C3C=C(O)C=C(O)C(=[O+]3)C=C(O)O2)cc([R])c1O</smiles>

$58 \mathrm{R} 1=\mathrm{H}, \quad \mathrm{R} 2=\mathrm{H}$

$59 \mathrm{R} 1=\mathrm{OH}, \quad \mathrm{R} 2=\mathrm{OH}$

$60 \mathrm{R} 1=\mathrm{OCH} 3, \mathrm{R} 2=\mathrm{OH}$ $61 \mathrm{R} 1=\mathrm{OCH} 3, \mathrm{R} 2=\mathrm{OCH} 3$

$62 \mathrm{R} 1=\mathrm{H}, \quad \mathrm{R} 2=\mathrm{OH}$

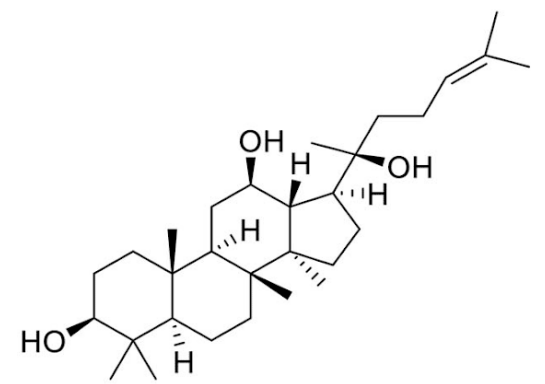

63<smiles>OCc1c[nH]c2ccccc12</smiles>

64<smiles>c1ccc2c(Cc3c[nH]c4ccccc34)c[nH]c2c1</smiles>

65

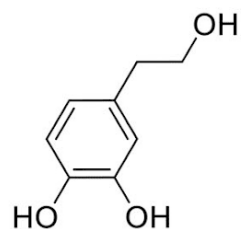

66 

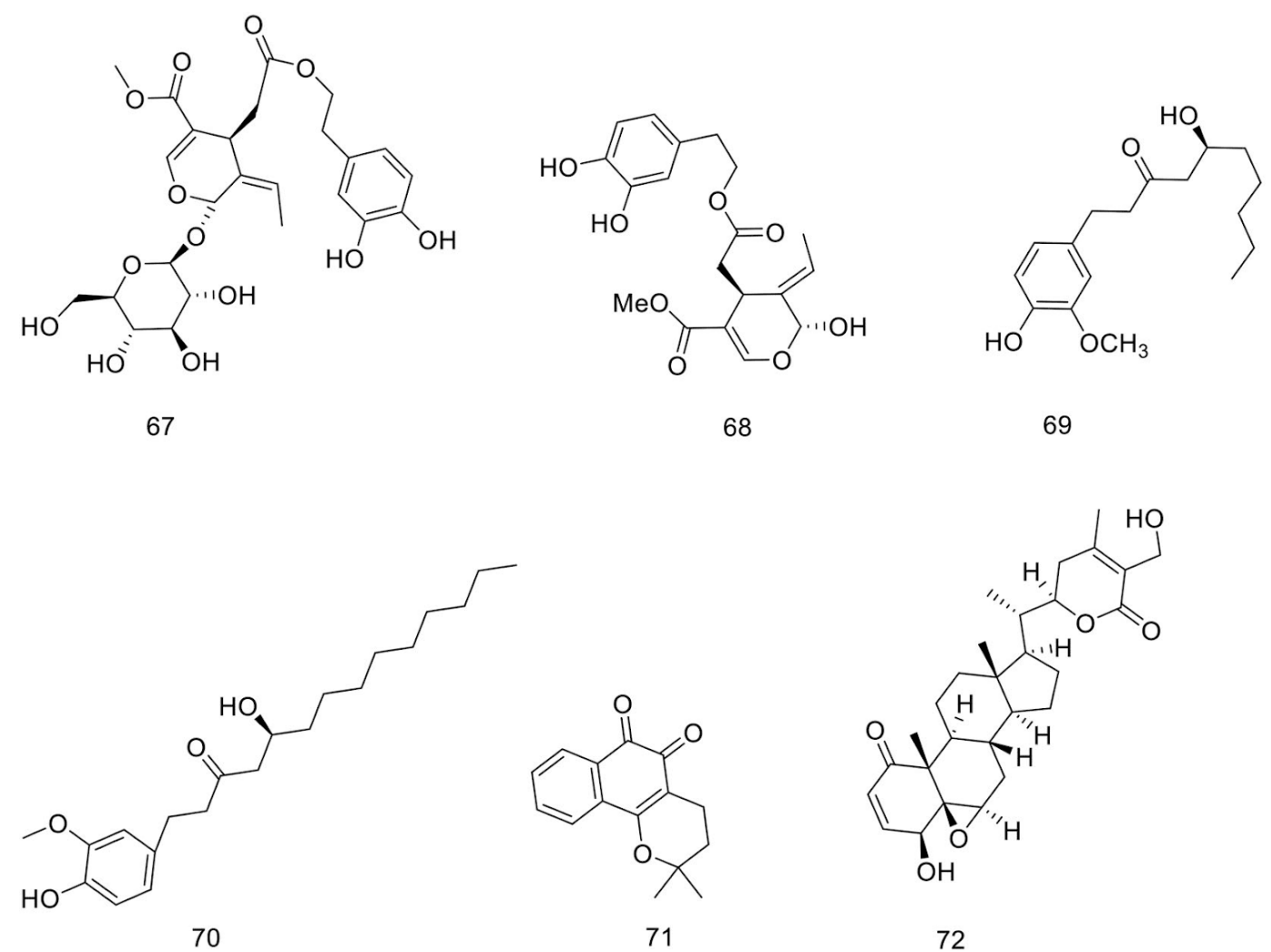<smiles>O=C(/C=C/c1ccc(O)cc1)c1ccc(O)cc1O</smiles>

73

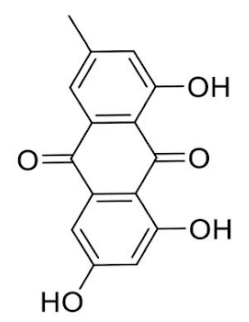

74

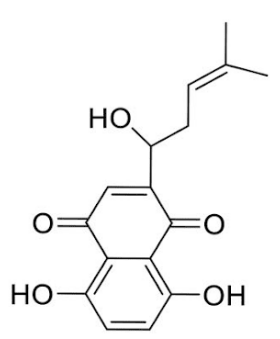

75

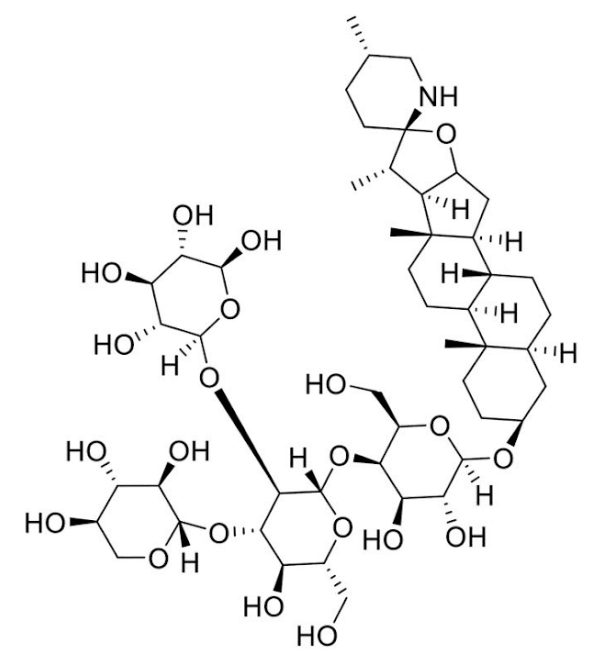

76

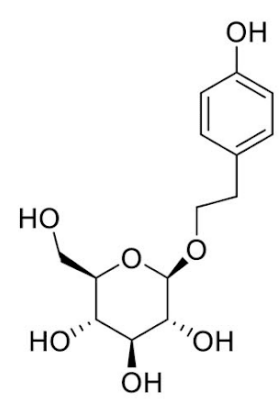

77

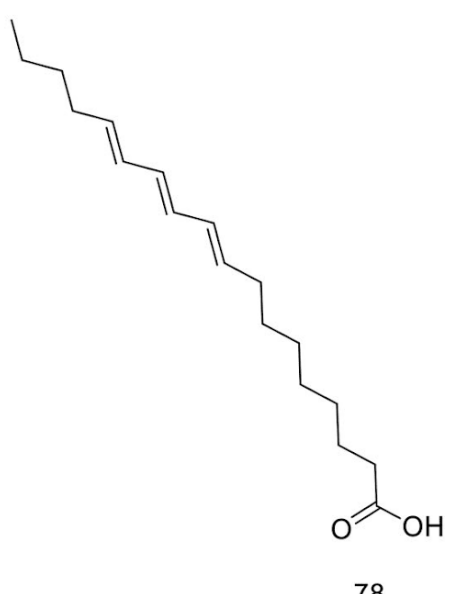

Figure 5. Continued. 
it showed the ability to inhibit cell adhesion, invasion, motility in MDA-MB-231 breast cancer cells through inhibition of activities and expression of MMP-2 and MMP-9, the extracellular matrix degrading enzymes (Lee et al. 2008). Mechanism of action of 10-gingerol (70), another gingerols derivative, was investigated since it showed inhibition of cell proliferation and invasion of breast cancer cells. Results demonstrated that it significantly suppressed the expression of Epidermal Growth Factor Receptor in estrogen-receptor negative MDA-MB-231 cells and ER-positive MCF-7 cells (Joo et al. 2016).

Beta-Lapachone (71) is a poorly soluble $o$-naphthoquinone compound containing aromatic ring combined to quinone subunits. It was firstly isolated from the tree Handroanthus impetiginosus and was also found in many plants. Its structure is highly reactive, and it displayed antiinflammatory and anti-cancer properties. Beta-lapachone has been proven to induce apoptotic or necrosis in various human cancer cells through mitochondrial cytochrome C-caspase pathway ( $\mathrm{Li}$ et al. 1999). Furthermore, it showed to react with the enzyme NAD (P) $\mathrm{H}$ quinone oxidoreductase (NQO1), a multifunctional antioxidant enzyme, then super- oxides production. The expression of NQO1 is highly expressed in diverse cancers, indicating a pivotal role in can- cer development. Beta-lapachone was also reported to induce cell death in MDA-MB-231 cells in an NQO1- dependent manner (Pardee, Li, and Li 2002; Kim and Cho 2018). Withaferin A (72), a C-28-steroidal lactone isolated from diverse Solanaceae plants such as Iochroma arborescens, Withania somnifera, is well known in ayurvedic medicine for its cardioprotective, antiinflammatory, antiangiogenesis, and anti-tumor properties. Investigation of its mechanism of action against MCF-7 and MDA-MB-231 breast cancer cell lines revealed that it silences HER2/PR/ ESR-dependent gene manifestation programs to suppress aggressive triple-negative breast cancer in favor of luminal BC hallmarks, improving the therapeutic sensitivity (vel Szic et al. 2017). Isoliquiritigenin (73) is a dietary compound of licorice root plants, especially from Glycyrrhiza glabra, which is used as a sweet flavoring. Isoliquiritigenin displayed a wide range of biological activities including anti-inflammatory, antimicrobial, antioxidative, anticancer, immunomodulatory, cardioprotective, and hepatoprotective activities. In breast cancer, isoliquiritigenin has been proven to inhibit angiogenesis by suppressing the vascular endothelial growth factor and the vascular endothelial growth factor receptor-2 VEGF/VEGF-2 pathways via promoting HIF-1a proteasome degradation (Peng et al. 2015). In mammary carcinogenesis, isoliquiritigenin showed inhibition of breast cancer stem cells through the DNA methyltransferase DNMT1-mediated Wnt inhibitory factor 1 demethylation, encouraging develop- ment of WF1 for breast cancer prevention (Wang et al. 2015). Emodin (74) is an anthraquinone found in barks and roots of numerous plants including Rheum officinale and Polygonum cuspidatum and molds and lichens, and it is used as a laxative. Emodin was reported as a tyrosine kinase inhibitor, inhibiting the growth of HER-2/neu overexpressing tumors and enhancing survival in athymic mice (Zhang et al. 1999). It also showed to induce apoptosis in human breast cancer cells BCap-37 through disruption of the mitochondrial signaling pathway (Huang, Chen, and Shi 2008). Shikonin (75) is a naphthoquinone pigment, found in the roots of the Chinese herbal plant Lithospermum erythrorhizon. Shikonin is known as an anti-inflammatory, antigonadotropic, anti-HIV agent. Investigations on its antiestrogen activity showed that it inhibited the growth of breast-tumor ERa-positive cells (Yao and Zhou 2010). Although it has proven to inhibit the activities DNA topoisomerases, suppressing the activity of pyruvate kinase M2 (PKM2) was also reported. Additionally, in combination with taxol, it showed to target Akt/p70S6K and ERKs (Li et al. 2014). a-Tomatine

(76) is a steroidal glycoalkaloid, present in the leaves, and roots of tomatoes and mainly known for its antiviral, anti-microbial and antiinflammatory properties. a-Tomatine showed inhibition of MCF-7 breast cancer cell proliferation, with an $\mathrm{EC}_{50}$ value of $7.17 \mathrm{mM}$ after $72 \mathrm{~h}$. Investigation on its mechanism of action revealed that it did not induce apoptosis, but a disruptive membrane effect might be involved due to its binding with membrane cholesterol (Sucha et al. 2013).

Salidroside (77) is a glucoside of tyrosol and extracted from plants of the genus Rhodiola, especially from the Chinese medicinal herb $R$. rosea. It showed antiviral, cardio-vascular and neuroprotective effects. Its inhibitory activity against human breast cancer cell line was studied on ER-positive MCF-7 and ER-negative MDA-MB-231 breast can- cer cells, showing that cell-cycle arrest leads to apoptosis by suppressing antiapoptotic proteins and might involve the mitochondrial pathway (Hu et al. 2010). Punicic acid (78) is a polyunsaturated fatty acid having omega-5 long-chain; mainly occurring in Punica granatum pomegranate seed oil (Shabbir et al. 2017). As most of the fatty acids having a long chain, it showed anti-cancer activity and revealed $92 \%$ and $96 \%$ inhibition of proliferation against ER-negative MDA-MB-231 and ERpositive MDA-ERa-7 human cancer cells at $40 \mathrm{mM}$, respectively (Grossmann et al. 2010). Chemical structures of dietary plants compounds showing mammary anticancer effects are shown in Figure 5.

\section{Conclusions}

Results of various in vitro and in vivo studies have demonstrated the potential of dietary phytochemicals in prevention and treatment of breast cancer. Several mechanistic studies have also confirmed the significance of plant phytochemicals against breast cancer. According to epidemiological studies, consumption of these dietary plant biologically active ingredients present in different fruits and vegetables is reported to be inversely associated with the risk of breast cancer. These naturally occurring plant-based phytochemicals possess potential breast anticancer perspectives via inducing apoptotic conditions, resulting in cell cycle arrest, down-regulating anti-apoptotic factors and inhibiting proliferation and metastasis of cancer cells. They help in the treatment of breast cancer through elevating the concentration of anti-oxidative enzymes, scavenging reactive oxygen species, and regulation of cell signaling pathways. Scientists are more focused on extraction, isolation and identification of the diverse class of phytochemicals from naturally occurring plants so that a better knowledge regarding their mode of action and toxicity could be understood. Additionally, pre-clinical and epidemiological trials must be carried out to optimize their potencies, metabolism, bioavailability, drug-nutrient interaction, and a better understanding of their pharmacokinetics. Conclusively, the various concentration of natural plant phytochemicals has been investigated as promising breast anticancer agents. Nevertheless, further clinical studies must be conducted to validate the suitable dose of administration of each phytochemical to be used in the treatment and prevention of breast cancer.

\section{Conflict of interest}

All the authors declare that there is no conflict of interest.

ORCID

Fahad A. Alhumaydhi

http://orcid.org/0000-0002-0151-8309 Kannan R. R. Rengasamy

http://orcid.org/0000-0001-7205-7389

References

Abdulkareem, I. H. 2013. Aetio-pathogenesis of breast cancer. Nigerian Medical Journal 54 (6):371-5. doi: 10.4103/0300-1652.126284.

ACS. 2019. Breast cancer: Facts \& figures 2019-2020. https://www.can- cer.org/content/dam/cancer-org/research/cancer-facts-and-statistics/ breast-cancer-factsand-figures/breast-cancer-facts-and-figures-2019- 2020.pdf.

Al Dhaheri, Y., S. Attoub, G. Ramadan, K. Arafat, K. Bajbouj, N. Karuvantevida, S. AbuQamar, A. Eid, and R. Iratni. 2014. Carnosol induces R0S-mediated beclin1independent autophagy and apop- tosis in triple negative breast cancer. PLoS One 9 (10):e109630. doi: 10.1371/journal.pone.0109630.

Alves-Silva, J. M., A. Romane, T. Efferth, and L. Salgueiro. 2017. North African medicinal plants traditionally used in cancer therapy. Frontiers in Pharmacology 8:383. doi: 10.3389/fphar.2017.00383.

Asif, H. M., S. Sultana, N. Akhtar, J. U. Rehman, and R. U. Rehman. 2014. Prevalence, risk factors and disease knowledge of breast cancer in Pakistan. Asian Pacific 
Journal of Cancer Prevention: APJCP 15 (11):4411-6. doi: 10.7314/APJCP.2014.15.11.4411.

Avila, M. A., J. A. Velasco, J. Cansado, and V. Notario. 1994. Quercetin mediates the down-regulation of mutant P53 in the human breast cancer cell line MDAMB468. Cancer Research 54 (9): 2424-8.

Badar, F., I. Moid, F. Waheed, A. Zaidi, B. Naqvi, and S. Yunus. 2005. Variables associated with recurrence in breast cancer patients: The Shaukat Khanum Memorial experience. Asian Pacific Journal of Cancer Prevention 6:54-7.

Balabhadrapathruni, S., T. J. Thomas, E. J. Yurkow, P. S. Amenta, and T. Thomas. 2000. Effects of genistein and structurally related phy- toestrogens on cell cycle kinetics and apoptosis in MDA-MB-468 human breast cancer cells. Oncology Reports 7 (1):3-15. doi: 10. 3892/or.7.1.3.

Balapure, S., and W. Wadegaonkar. 2014. Determination of antitrypsin activity of lupeol by Folin Lowery method. The International Journal of Science and Technoledge $2(4): 1$.

Baldassano, S., A. Rotondo, R. Serio, M. A. Livrea, L. Tesoriere, and F. Mul' e. 2011. Inhibitory effects of indicaxanthin on mouse ileal con- tractility: Analysis of the mechanism of action. European Journal of Pharmacology 658 (2-3):200-5. doi: 10.1016/j.ejphar.2011.02.034.

Barreca, D., G. Gattuso, E. Bellocco, A. Calderaro, D. Trombetta, A. Smeriglio, G. Lagan' a, M. Daglia, S. Meneghini, and S. M. Nabavi. 2017. Flavanones: Citrus phytochemical with health-promoting properties. BioFactors (Oxford, England) 43 (4):495-506. doi: 10. 1002/biof.1363.

Bhagwat, S., D. B. Haytowitz, and J. M. Holden. 2014. USDA database for the flavonoid content of selected foods: Release 3.1. Beltsville, MD: US Department of Agriculture. https://www.ars.usda.gov/ ARSUserFiles/80400535/Data/Flav/Flav_R03-1.pdf.

Bhurgri, Y. 2004. Karachi Cancer Registry Data: Implications for the National Cancer Control Program of Pakistan. Asian Pacific Journal of Cancer Prevention 5 (1):77-82.

Blaskovich, M. A., J. Sun, A. Cantor, J. Turkson, R. Jove, S. Sa1€D, and M. Sebti. 2003. Discovery of JSI-124 (cucurbitacin I), a selective janus kinase/signal transducer and activator of transcription 3 sig-naling pathway inhibitor with potent antitumor activity against human and murine cancer cells in mice 1 . Cancer Research 63 (6): 1270-9.

Block, E. 1985. The chemistry of garlic and onions. Scientific American 252 (3):114-9. doi: 10.1038/scientificamerican0385-114.

Bonetti, F., G. Brombo, and G. Zuliani. 2017. Nootropics, functional foods, and dietary patterns for prevention of cognitive decline. In Nutrition and functional foods for healthy aging, 211-32. Cambridge, MA: Academic Press. doi: 10.1016/B978-0-12-805376-8.00019-8.

Brat, P. 2008. Rapid analysis of phytochemicals in fruit and vegetables. In Improving the health-promoting properties of fruit and vegetable products, $248-78$. Sawston, UK: Woodhead Publishing. doi: 10.1533/ 9781845694289.3.248.

Castro, N. P., M. C. Rangel, A. S. Merchant, G. MacKinnon, F. Cuttitta, D. S. Salomon, and Y. S. Kim. 2019. Sulforaphane sup- presses the growth of triple-negative breast cancer stem-like cells in vitro and in vivo. Cancer Prevention Research (Philadelphia, Pa.) 12 (3):147-58. doi: 10.1158/1940-6207.CAPR-18-0241.

Chakravarti, B., R. Maurya, J. A. Siddiqui, H. Kumar Bid, S. M. Rajendran, P. P. Yadav, and R. Konwar. 2012. In vitro anti-breast cancer activity of ethanolic extract of Wrightia tomentosa: Role of pro-apoptotic effects of oleanolic acid and urosolic acid. Journal of Ethnopharmacology 142 (1):72-9. doi: 10.1016/j.jep.2012.04.015.

Chan, W. H. 2007. The signaling cascades of ginkgolide B-induced apoptosis in MCF-7 breast cancer cells. International Journal of Molecular Sciences 8 (11):1177-95. doi: $10.3390 /$ i8111177.

Chang, C. J., J. H. Chiu, L. M. Tseng, C. H. Chang, T. M. Chien, C. W. Wu, and W. Y. Lui. 2006. Modulation of HER2 expression by ferulic acid on human breast cancer MCF7 cells. European Journal of Clinical Investigation 36 (8):588-96. doi: 10.1111/j.1365-2362. 2006.01676.x.

Chen, J. C., M. H. Chiu, R. L. Nie, G. A. Cordell, and S. X. Qiu. 2005. Cucurbitacins and cucurbitane glycosides: Structures and biological activities. Natural Product Reports 22 (3):386-99. doi: 10.1039/ B418841C.

Chew, B. P., C. M. Brown, J. S. Park, and P. F. Mixter. 2003. Dietary lutein inhibits mouse mammary tumor growth by regulating angio- genesis and apoptosis. Anticancer Research 23:3333-9.

Choi, E. J. 2007. Hesperetin induced G1-phase cell cycle arrest in human breast cancer MCF-7 cells: Involvement of CDK4 and P21. Nutrition and Cancer 59 (1):115-9. doi: 10.1080/01635580701419030.

Choi, E. J., and W. S. Ahn. 2008. Kaempferol induced the apoptosis via cell cycle arrest in human breast cancer MDA-MB-453 cells. Nutrition Research and Practice 2 (4):322-5. doi: $10.4162 /$ nrp.2008.2. 4.322.

Choi, J. A., J. Y. Kim, J. Y. Lee, C. M. Kang, H. J. Kwon, Y. D. Yoo, T. W. Kim, Y. S. Lee, and S. J. Lee. 2001. Induction of cell cycle arrest and apoptosis in human breast cancer cells by quercetin. International Journal of Oncology 19 (4):837-44. doi: 10.3892/ijo.19. 4.837.

Choi, Y. H., L. Zhang, W. H. Lee, and K. Y. Park. 1998. Genistein- induced G2/M arrest is associated with the inhibition of cyclin B1 and the induction of P21 in human breast carcinoma cells. International Journal of Oncology 13 (2):391-6. doi: 10.3892/ijo.13.2. 391.

Ciolino, H. P., and G. C. Yeh. 1999. The flavonoid galangin is an inhibitor of CYP1A1 activity and an agonist/antagonist of the aryl hydrocarbon receptor. British Journal of Cancer 79 (9-10):1340-6. doi: 10.1038/sj.bjc.6690216.

Crowell, P. L. 1997. Monoterpenes in breast cancer chemoprevention. Breast Cancer Research and Treatment 46 (2-3):191-7. doi: 10.1023/ A:1005939806591.

Danbara, N., T. Yuri, M. Tsujita-Kyutoku, R. Tsukamoto, N. Uehara, and A. Tsubura. 2005. Enterolactone induces apoptosis and inhibits growth of Colo 201 human colon cancer cells both in vitro and in vivo. Anticancer Research 25 (3B):2269-76.

Deng, Y. T., H. C. Huang, and J. K. Lin. 2010. Rotenone induces apop- tosis in MCF-7 human breast cancer cell-mediated ROS through JNK and P38 signaling. Molecular Carcinogenesis 49 (2):141-51. doi: 10.1002/mc.20583.

De Oliveira, M. R., S. F. Nabavi, S. Habtemariam, I. E. Orhan, M. Daglia, and S. M. Nabavi. 2015. The effects of baicalein and baicalin on mitochondrial function and dynamics: A review. Pharmacological Research 100:296-308. doi: 10.1016/j.phrs.2015.08.021.

De Pascual-Teresa, S., D. A. Moreno, and C. Garc' 1a-Viguera. 2010. Flavanols and anthocyanins in cardiovascular health: A review of current evidence. International Journal of Molecular Sciences 11 (4): 1679-703. doi: 10.3390/ijms11041679.

DeSantis, C., J. Ma, L. Bryan, and A. Jemal. 2014. Breast cancer statis- tics, 2013. CA: A Cancer Journal for Clinicians 64 (1):52-62. doi: 10. $3322 /$ caac.21203.

DeSantis, C., R. Siegel, P. Bandi, and A. Jemal. 2011. Breast cancer sta- tistics, 2011. CA: A Cancer Journal for Clinicians 61 (6):408-18. doi: 10.3322/caac.20134.

Duvoix, A., R. Blasius, S. Delhalle, M. Schnekenburger, F. Morceau, E. Henry, M. Dicato, and M. Diederich. 2005. Chemopreventive and therapeutic effects of curcumin. Cancer Lett 223 (2):181-90. doi: 10. 1016/j.canlet.2004.09.041.

Einbond, L. S., H. A. Wu, R. Kashiwazaki, K. He, M. Roller, T. Su, X. Wang, and S. Goldsberry. 2012. Carnosic acid inhibits the growth of ER-negative human breast cancer cells and synergizes with curcu- min. Fitoterapia 83 (7):1160-8. doi: 10.1016/j.fitote.2012.07.006.

El-Seedi, H. R., A. M. A. El-Said, S. A. M. Khalifa, U. Go€ransson, L. Bohlin, A. K. Borg-Karlson, and R. Verpoorte. 2012. Biosynthesis, natural sources, dietary intake, pharmacokinetic properties, and bio- logical activities of hydroxycinnamic acids. Journal of Agricultural and Food Chemistry 60 (44):10877-95. doi: $10.1021 /$ jf301807g

Endo, Y., K. Mitsui, M. Motizuki, and K. Tsurugi. 1987. The mechan- ism of action of ricin and related toxic lectins on eukaryotic ribo- somes. The site and the characteristics of the modification in $28 \mathrm{~S}$ ribosomal RNA caused by the toxins. Journal of Biological Chemistry 262 (12):5908-12.

Fern' andez, M. A., B. de las Heras, M. D. Garcia, M. T. S' aenz, and A. Villar. 2001. New insights into the mechanism of action of the anti- inflammatory triterpene lupeol. The Journal of Pharmacy and Pharmacology 53 (11):1533-9. doi: 10.1211/0022357011777909.

Friebel, T. M., S. M. Domchek, and T. R. Rebbeck. 2014. Modifiers of cancer risk in BRCA1 and BRCA2 mutation carriers: Systematic review and meta-analysis. Journal of the National Cancer Institute 106 (6):dju091. doi: 10.1093/jnci/dju091.

Gaudet, M. M., S. M. Gapstur, J. Sun, W. R. Diver, L. M. Hannan, and M. J. Thun. 2013. Active smoking and breast cancer risk: Original cohort data and metaanalysis. Journal of the National Cancer Institute 105 (8):515-25. doi: 10.1093/jnci/djt023.

Giovannucci, E. 1999. Tomatoes, tomato-based products, lycopene, and cancer: review of the epidemiologic literature. Journal of the National Cancer Institute 91 (4):317-31. doi: $10.1093 /$ jnci/91.4.317.

Goncharov, N., A. N. Orekhov, N. Voitenko, A. Ukolov, R. Jenkins, and P. Avdonin. 2016. Organosulfur compounds as nutraceuticals. In Nutraceuticals: Efficacy, safety and toxicity, 555-68. Cambridge, MA: Academic Press. doi: 10.1016/B978-0-12-802147-7.00041-3.

Grossmann, M. E., N. K. Mizuno, T. Schuster, and M. P. Cleary. 2010. Punicic acid is an $x-5$ fatty acid capable of inhibiting breast cancer proliferation. International Journal of Oncology 36 (2):421-6. doi:10. 3892/ijo_00000515.Gu, J. W., K. L. Makey, K. B. Tucker, E. Chinchar, X. Mao, I. Pei, E. Y. Thomas, and L. Miele. 2013. EGCG, a major green tea cat- echin suppresses breast tumor angiogenesis and growth via inhibit-ing the activation of HIF-1a and NF/B, and VEGF expression. Vascular Cell 5 (1):9-10. doi: 10.1186/2045-824X-5-9.

Hammerstone, J. F., S. A. Lazarus, and H. H. Schmitz. 2000. Procyanidin content and variation in some commonly consumed foods. The Journal of Nutrition 130 (8S Suppl):2086S-92S. doi: 10. 1093/jn/130.8.2086S.

Han, J., T. P. N. Talorete, P. Yamada, and H. Isoda. 2009. Anti-prolif- erative and apoptotic effects of oleuropein and hydroxytyrosol on human breast cancer MCF-7 cells. Cytotechnology 59 (1):45-53. doi: 10.1007/s10616-009-9191-2.

Haris Omar, S. 2010. Oleuropein in olive and its pharmacological effects. Scientia Pharmaceutica 78 (2):133-54. doi: 10.3797/scipharm. 0912-18.

Harnly, J. M., R. F. Doherty, G. R. Beecher, J. M. Holden, D. B. Haytowitz, S. Bhagwat, and S. Gebhardt. 2006. Flavonoid content of 
U.S. fruits, vegetables, and nuts. Journal of Agricultural and Food Chemistry 54 (26):9966-77. doi: 10.1021/jf061478a.

Hawsawi, Y. M., N. S. Al-Numair, T. M. Sobahy, A. M. Al-Ajmi, R. M. Al-Harbi, M. A. Baghdadi, A. A. Oyouni, and 0. M. Alamer. 2019. The role of BRCA1/2 in hereditary and familial breast and ovarian cancers. Molecular Genetics \& Genomic Medicine 7 (9):e879. doi: 10. 1002/mgg3.879.

Howlader, N., A. M. Noone, M. Krapcho, D. Miller, K. Bishop, C. L. Kosary, M. Yu, J. Ruhl, Z. Tatalovich, A. Mariotto, et al. 2017. SEER cancer statistics review, 19752014. Bethesda, MD: National Cancer Institute. https://seer.cancer.gov/csr/1975_2014/, based on November 2016 SEER data submission, posted to the SEER web site.

Howlader, N., A. M. Noone, M. Krapcho, D. Miller, A. Brest, M. Yu, J. Ruhl, Z. Tatalovich, A. Mariotto, D. R. Lewis, et al. 2019. SEER can- cer statistics review, $1975-2016$. Bethesda, MD: National Cancer Institute. https://seer.cancer.gov/csr/1975_2016/, based on November 2018 SEER data submission, posted to the SEER web site.

He, X., and R. H. Liu. 2008. Phytochemicals of apple peels: Isolation, structure elucidation, and their antiproliferative and antioxidant activities. Journal of Agricultural and Food Chemistry 56 (21): 9905-10. doi: 10.1021/jf8015255.

Hirsch, K., M. Danilenko, J. Giat, T. Miron, A. Rabinkov, M. Wilchek, D. Mirelman, J. Levy, and Y. Sharoni. 2000. Effect of purified allicin, the major ingredient of freshly crushed garlic, on cancer cell prolif- eration. Nutrition and Cancer 38 (2):245-54. doi: 10.1207/ S15327914NC382 14.

Horn, J., and L. J. Vatten. 2017. Reproductive and hormonal risk fac- tors of breast cancer: A historical perspective. International Journal of Women's Health 9:26572. doi: 10.2147/IJWH.S129017.

Hsu, J. D., S. H. Kao, T. T. Ou, Y. J. Chen, Y. J. Li, and C. J. Wang. 2011. Gallic acid induces G2/M phase arrest of breast cancer cell MCF-7 through stabilization of P27Kip1 attributed to disruption of P27 Kip1/Skp2 complex. Journal of Agricultural and Food Chemistry 59 (5):1996-2003. doi: 10.1021/jf103656v.

$\mathrm{Hu}$, X., X. Zhang, S. Qiu, D. Yu, and S. Lin. 2010. Salidroside induces cell-cycle arrest and apoptosis in human breast cancer cells. Biochemical and Biophysical Research Communications 398 (1):62-7. doi: 10.1016/j.bbrc.2010.06.033.

Huang, J., B. Yang, T. Xiang, W. Peng, Z. Qiu, J. Wan, L. Zhang, H. Li, H. Li, and G. Ren. 2015. Diallyl disulfide inhibits growth and metastatic potential of human triple-negative breast cancer cells through inactivation of the b-catenin signaling pathway. Molecular Nutrition \& Food Research 59 (6):1063-75. doi: $10.1002 / \mathrm{mnfr} .201400668$.

Huang, Z., G. Chen, and P. Shi. 2008. Emodin-induced apoptosis in human breast cancer BCap-37 cells through the mitochondrial sig- naling pathway. Archives of Pharmacal Research 31 (6):742-8. doi: 10.1007/s12272-001-1221-6.

Hussain, A., J. Mohsin, S. A. Prabhu, S. Begum, Q. E. A. Nusri, G. Harish, E. Javed, M. A. Khan, and C. Sharma. 2013. Sulforaphane inhibits growth of human breast cancer cells and augments the therapeutic index of the chemotherapeutic drug, gemcitabine. Asian Pacific Journal of Cancer Prevention 14 (10):5855-60. doi: 10.7314/ APJCP.2013.14.10.5855.

Iqbal, J., B. A. Abbasi, T. Mahmood, S. Kanwal, B. Ali, S. A. Shah, and A. T. Khalil. 2017. Plant-derived anticancer agents: A green anti- cancer approach. Asian Pacific Journal of Tropical Biomedicine 7 (12):1129-50. doi: 10.1016/j.apjtb.2017.10.016.

Jang, M., L. Cai, G. O. Udeani, K. V. Slowing, C. F. Thomas, C. W. Beecher, H. H. Fong, N. R. Farnsworth, A. D. Kinghorn, R. G. Mehta, et al. 1997. Cancer chemopreventive activity of resveratrol, a natural product derived from grapes. Science (New York, N.Y.) 275 (5297):218-20.,doi: 10.1126/science.275.5297.218.

Jemal, A., R. Siegel, E. Ward, Y. Hao, J. Xu, T. Murray, and M. J. Thun. 2008. Cancer statistics, 2008. CA: A Cancer Journal for Clinicians 58 (2):71-96. doi: 10.3322/CA.2007.0010.

Jemal, A., R. Siegel, E. Ward, Y. Hao, J. Xu, and M. J. Thun. 2009. Cancer statistics, 2009. CA: A Cancer Journal for Clinicians 59 (4): 225-249. doi: 10.3322/caac.20006.

Jemal, A., R. Siegel, E. Ward, T. Murray, J. Xu, C. Smigal, and M. J. Thun. 2006. Cancer statistics, 2006. CA: A Cancer Journal for Clinicians 56 (2):106-30. doi: 10.3322/canjclin.56.2.106.

Jemal, A., R. Siegel, J. Xu, and E. Ward. 2010. Cancer statistics, 2010. CA: A Cancer Journal for Clinicians 60 (5):277-300. doi: 10.3322/ caac.20073.

Jemal, A., R. C. Tiwari, T. Murray, A. Ghafoor, A. Samuels, E. Ward, E. J. Feuer, and M. J. Thun. 2004. Cancer statistics, 2004. CA: A Cancer Journal for Clinicians 54 (1):8-29. doi: 10.3322/canjclin.54.1. 8.

Jesus, J. A. J. H. G. Lago, M. D. Laurenti, E. S. Yamamoto, and L. F. D. Passero. 2015. Antimicrobial activity of oleanolic and ursolic acids: An update. EvidenceBased Complementary and Alternative Medicine: eCAM 2015:620472-14. doi: 10.1155/2015/620472.

Jiang, N., A. I. Doseff, and E. Grotewold. 2016. Flavones: From biosyn-thesis to health benefits. Plants 5 (2):27. doi: 10.3390/plants5020027. Jin, S., Q. Y. Zhang, X. M. Kang, J. X. Wang, and W. H. Zhao. 2010. Daidzein induces MCF-7 breast cancer cell apoptosis via the mito- chondrial pathway. Annals of Oncology 21 (2):263-8. doi: 10.1093/annonc/mdp499.

Jin, Y. 2011. 3, $3^{0}$-Diindolylmethane inhibits breast cancer cell growth via MiR-21-mediated Cdc25A degradation. Molecular and Cellular Biochemistry 358 (12):345-54. doi: 10.1007/s11010-011-0985-0.

Joo, J. H., S. S. Hong, Y. R. Cho, and D. W. Seo. 2016. 10-Gingerol inhibits proliferation and invasion of MDA-MB-231 breast cancer cells through suppression of Akt and P38MAPK activity. Oncology Reports 35 (2):779-84. doi: 10.3892/or.2015.4405.

Kampa, M., V.-I. Alexaki, G. Notas, A.-P. Nifli, A. Nistikaki, A. Hatzoglou, E. Bakogeorgou, E. Kouimtzoglou, G. Blekas, D. Boskou, et al. 2004. Antiproliferative and apoptotic effects of selective phen- olic acids on T47D human breast cancer cells: Potential mechanisms of action. Breast Cancer Research: BCR 6 (2):R63-74. doi: $10.1186 /$ bcr752.

Kanimozhi, G., and N. R. Prasad. 2015. Anticancer effect of caffeic acid on human cervical cancer cells. In Coffee in health and disease pre- vention, 655-61. Cambridge, MA: Academic Press. doi: 10.1016/ B978-0-12-409517-5.00073-5.

Kapadia, G. J., G. S. Rao, C. Ramachandran, A. Iida, N. Suzuki, and H. Tokuda. 2013. Synergistic cytotoxicity of red beetroot (Beta vulgaris L.) extract with doxorubicin in human pancreatic, breast and pros- tate cancer cell lines. Journal of Complementary \& Integrative Medicine 10:113-22. doi: 10.1515/jcim-2013-0007.

Kassi, E., T. G. Sourlingas, M. Spiliotaki, Z. Papoutsi, H. Pratsinis, N. Aligiannis, and P. Moutsatsou. 2009. Ursolic acid triggers apoptosis and Bcl-2 downregulation in MCF-7 breast cancer cells. Cancer Investigation 27 (7):723-33. doi: 10.1080/07357900802672712.

Kaufman, P. B., J. A. Duke, H. Brielmann, J. Boik, and J. E. Hoyt. 1997. A comparative survey of leguminous plants as sources of the isoflavones, genistein and daidzein: Implications for human nutri- tion and health. Journal of Alternative and Complementary Medicine 3 (1):7-12. doi: 10.1089/acm.1997.3.7.

Kesarkar, S., A. Bhandage, S. Deshmukh, K. Shevkar, and M. Abhyankar. 2009. Flavonoids: An overview. Journal of Pharmacy Research 2:1148-54. doi: 10.1017/jns.2016.41.

Khalil, A. A., M. R. Khan, M. A. Shabbir, and K. U. Rahman. 2017. Comparison of antioxidative potential and punicalagin content of pomegranate peels. Journal of Animal and Plant Sciences 27 (2): 522-7.

Khalil, A. A., M. R. Khan, M. A. Shabbir, and K. U. Rahman. 2018. In vitro antioxidant activity and punicalagin content quantification of pomegranate peel obtained as agro-waste after juice extraction. Pakistan Journal of Agricultural Sciences 55 (01):197-201. doi: 10. 21162/PAKJAS/18.5663.

Khoo, H. E., A. Azlan, S. T. Tang, and S. M. Lim. 2017. Anthocyanidins and anthocyanins: Colored pigments as food, pharmaceutical ingredients, and the potential health benefits. Food \& Nutrition Research 61 (1):1361779. doi: 10.1080/16546628.2017. 1361779.

Kim, D. W., and J. Y. Cho. 2018. NQO1 is required for b-lapachone- mediated downregulation of breast-cancer stem-cell activity. International Journal of Molecular Sciences 19 (12):3813. doi: 10. 3390/ijms19123813.

Kim, S., S. H. Kim, S. M. Hur, S.-K. Lee, W. W. Kim, J. S. Kim, J.-H. Kim, J.-H. Choe, S. J. Nam, J. E. Lee, et al. 2009. Silibinin prevents TPA-induced MMP-9 expression by down-regulation of COX-2 in human breast cancer cells. Journal of Ethnopharmacology 126 (2): 252-7. doi: 10.1016/j.jep.2009.08.032.

Kim, Y., K. Y. Yoo, and M. T. Goodman. 2015. Differences in inci- dence, mortality and survival of breast cancer by regions and coun- tries in Asia and contributing factors. Asian Pacific Journal of Cancer Prevention: APJCP 16 (7):2857-70. doi: 10.7314/apjcp.2015. 16.7.2857.

Kispert, S., and J. McHowat. 2017. Recent insights into cigarette smok- ing as a lifestyle risk factor for breast cancer. Breast Cancer (Dove Medical Press) 9:127-32. doi: 10.2147/BCTT.S129746.

Kitts, D. D., Y. V. Yuan, A. N. Wijewickreme, and L. U. Thompson. 1999. Antioxidant activity of the flaxseed lignan secoisolariciresinol diglycoside and its mammalian lignan metabolites enterodiol and enterolactone. Molecular and Cellular Biochemistry 202 (1/2):91-100. doi: 10.1023/A:1007022329660.

Krinsky, N. I., J. T. Landrum, and R. A. Bone. 2003. Biologic mecha- nisms of the protective role of lutein and zeaxanthin in the eye. Annual Review of Nutrition 23:171-201. doi: 10.1146/annurev.nutr. 23.011702.073307.

Kuchenbaecker, K. B., J. L. Hopper, D. R. Barnes, K.-A. Phillips, T. M. Mooij, M.-J. Roos-Blom, S. Jervis, F. E. van Leeuwen, R. L. Milne, N. Andrieu, et al. 2017. Risks of breast, ovarian, and contralateral breast cancer for BRCA1 and BRCA2 mutation carriers. JAMA 317 (23):2402-16. doi: 10.1001/jama.2017.7112.

Kumar, N., and V. Pruthi. 2014. Potential applications of ferulic acid from natural sources. Biotechnology Reports (Amsterdam, Netherlands) (4):86-93. doi: 10.1016/j.btre.2014.09.002.

Kumar, S., and A. K. Pandey. 2013. Chemistry and biological activities of flavonoids: An overview. The Scientific World Journal 2013:1-16. doi: $10.1155 / 2013 / 162750$.

Lamartiniere, C. A. 2000. Protection against breast cancer with genis- tein: A component of soy. The American Journal of Clinical Nutrition 71 (6 Suppl):1705S-7S. doi: 10.1093/ajcn/71.6.1705s. 
Lambertini, E., I. Lampronti, L. Penolazzi, M. T. Hassan Khan, A. Ather, G. Giorgi, R. Gambari, and R. Piva. 2005. Expression of estrogen receptor a gene in breast cancer cells treated with tran- scription factor decoy is modulated by Bangladeshi natural plant extracts. Oncology Research 15 (2):69-79. doi: 10.3727/ 096504005775082057.

Langcake, P., and R. J. Pryce. 1977. A new class of phytoalexins from grapevines. Experientia 33 (2):151-2. doi: 10.1007/BF02124034.

Lason', W., and M. Le' skiewicz. 2013. Effect of plant polyphenols on seizures: Animal studies. Journal of Epileptology 21 (2):79-87. doi: 10.1515/joepi-20150007.

Le, H. T., C. M. Schaldach, G. L. Firestone, and L. F. Bjeldanes. 2003. Plant-derived 3,30 -diindolylmethane is a strong androgen antagonist in human prostate cancer cells. The Journal of Biological Chemistry 278 (23):21136-45. doi: 10.1074/jbc.M300588200.

Lechner, J. F., L. S. Wang, C. M. Rocha, B. Larue, C. Henry, C. M. McIntyre, K. M. Riedl, S. J. Schwartz, and G. D. Stoner. 2010. Drinking water with red beetroot food color antagonizes esophageal carcinogenesis in N-nitrosomethylbenzylamine-treated rats. Journal of Medicinal Food 13 (3):733-9. doi: 10.1089/jmf.2008.0280.

Le Corre, L., N. Chalabi, L. Delort, Y. J. Bignon, and D. J. Bernard- Gallon. 2005. Resveratrol and breast cancer chemoprevention: Molecular mechanisms. Molecular Nutrition \& Food Research 49 (5): 462-71. doi: 10.1002/mnfr.200400094.

Lee, C. G., H. W. Lee, B. O. Kim, D. K. Rhee, and S. Pyo. 2015. Allicin inhibits invasion and migration of breast cancer cells through the suppression of VCAM-1: regulation of association between P65 and ER-a. Journal of Functional Foods 15:172-85. doi: 10.1016/j.jff.2015. 03.017.

Lee, E. J., S. Y. Oh, and M. K. Sung. 2012. Luteolin exerts anti-tumor activity through the suppression of epidermal growth factor receptor-mediated pathway in MDA-MB-231 ER-negative breast cancer cells. Food and Chemical Toxicology 50 (11):4136-43. doi: 10.1016/j. fct.2012.08.025

Lee, H. S., E. Y. Seo, N. E. Kang, and W. K. Kim. 2008. [6]-Gingerol inhibits metastasis of MDA-MB-231 human breast cancer cells. The Journal of Nutritional Biochemistry 19 (5):313-9. doi: 10.1016/j.jnut- bio.2007.05.008.

Levy, J., E. Bosin, B. Feldman, Y. Giat, A. Miinster, M. Danilenko, and Y. Sharoni. 1995. Lycopene is a more potent inhibitor of human cancer cell proliferation than either alpha-carotene or beta-carotene. Nutrition and Cancer 24 (3):257-66. doi: 10.1080/ 01635589509514415.

Li, W., J. Liu, K. Jackson, R. Shi, and Y. Zhao. 2014. Sensitizing the therapeutic efficacy of taxol with shikonin in human breast cancer cells. PLoS One 9 (4):e94079. doi: 10.1371/journal.pone.0094079.

Li, Y., T. Zhang, H. Korkaya, S. Liu, H. F. Lee, B. Newman, Y. Yu, S. G. Clouthier, S. J. Schwartz, M. S. Wicha, et al. 2010. Sulforaphane, a dietary component of broccoli/broccoli sprouts, inhibits breast cancer stem cells. Clinical Cancer Research 16 (9): 2580-90. doi: 10.1158/1078-0432.CCR-09-2937.

Li, Y. Z., C. J. Li, A. V. Pinto, and A. B. Pardee. 1999. Release of mito- chondrial cytochrome C in both apoptosis and necrosis induced by $b$-lapachone in human carcinoma cells. Molecular Medicine 5 (4): 232-9. doi: 10.1007/BF03402120.

Liggins, J., L. J. C. Bluck, S. Runswick, C. Atkinson, W. A. Coward, and S. A. Bingham. 2000. Daidzein and genistein content of fruits and nuts. Journal of Nutritional Biochemistry 11 (6):326-31. doi: 10. 1016/S0955-2863(00)00085-1.

Liu, Y., N. Nguyen, and G. A. Colditz. 2015. Links between alcohol consumption and breast cancer: A look at the evidence. Women's Health (London, England) 11 (1):65-77. doi: 10.2217/WHE.14.62.

Lo, A. H., Y. C. Liang, S. Y. Lin-Shiau, C. T. Ho, and J. K. Lin. 2002. Carnosol, an antioxidant in rosemary, suppresses inducible nitric oxide synthase through downregulating nuclear factor-kappaB in mouse macrophages. Carcinogenesis 23 (6):983-91. doi: 10.1093/car- cin/23.6.983.

Lopez-Lazaro, M. 2009. Distribution and biological activities of the fla- vonoid luteolin. Mini-Reviews in Medicinal Chemistry 9 (1):31-59. doi: $10.2174 / 138955709787001712$.

Lu, W., C. Lin, T. D. King, H. Chen, R. C. Reynolds, and Y. Li. 2012. Silibinin inhibits Wnt/b-catenin signaling by suppressing Wnt co- receptor LRP6 expression in human prostate and breast cancer cells. Cellular Signalling 24 (12):2291-6. doi: 10.1016/j.cellsig.2012.07.009.

Luo, X. J., J. Peng, and Y. J. Li. 2011. Recent advances in the study on capsaicinoids and capsinoids. European Journal of Pharmacology 650 (1):1-7. doi: 10.1016/j.ejphar.2010.09.074.

Maheshwari, R. K., A. K. Singh, J. Gaddipati, and R. C. Srimal. 2006. Multiple biological activities of curcumin: A short review. Life Sciences 78 (18):2081-7. doi: 10.1016/j.lfs.2005.12.007.

Mashhadi, N. S., R. Ghiasvand, G. Askari, M. Hariri, L. Darvishi, and M. R. Mofid. 2013. Anti-oxidative and anti-inflammatory effects of ginger in health and physical aactivity: Review of current evidence. International Journal of Preventive Medicine 4 (Suppl 1):S36-S42. Mbaveng, A. T., R. Hamm, and V. Kuete. 2014. Harmful and protect-ive effects of terpenoids from African medicinal plants. In Toxicological survey of African medicinal plants, 557-76. Amsterdam, the Netherlands: Elsevier Inc. doi: 10.1016/B978-0-12- 800018-2.00019-4.

McGarvey, D. J., and R. Croteau. 1995. Terpenoid metabolism. The Plant Cell 7 (7):1015-26. doi: 10.1105/tpc.7.7.1015.

Menendez, J. A., A. Vazquez-Martin, R. Colomer, J. Brunet, A. Carrasco-Pancorbo, R. Garcia-Villalba, A. Fernandez-Gutierrez, and Segura-Carretero. 2007. Olive oil's bitter principle reverses acquired autoresistance to trastuzumab (Herceptin) in HER2-overex- pressing breast cancer cells. BMC Cancer 7 (1):80. doi: 10.1186/ 1471-2407-7-80.

Mertens-Talcott, S. U., G. D. Noratto, X. Li, G. Angel-Morales, M. C. Bertoldi, and S. Safe. 2013. Betulinic acid decreases ER-negative breast cancer cell growth in vitro and in vivo: Role of Sp transcrip- tion factors and microRNA-27a:ZBTB10. Molecular Carcinogenesis 52 (8):591-602. doi: 10.1002/mc.21893.

Misawa, N. 2010. Carotenoids. In Comprehensive natural products II, 733-53. Amsterdam, the Netherlands: Elsevier Inc. doi: 10.1016/ B978-008045382-8.00009-5.

Molavi, O., F. Narimani, F. Asiaee, S. Sharifi, V. Tarhriz, A. Shayanfar, M. Hejazi, and R. Lai. 2017. Silibinin sensitizes chemo-resistant breast cancer cells to chemotherapy. Pharmaceutical Biology 55 (1): 729-39. doi: 10.1080/13880209.2016.1270972.

Momenimovahed, Z., and H. Salehiniya. 2019. Epidemiological charac- teristics of and risk factors for breast cancer in the world. Breast Cancer (Dove Medical Press) 11:151-64. doi: 10.2147/BCTT.S176070. Monsereenusorn, Y., S. Kongsamut, P. D. Pezalla, and T. L. Yaksh. 1982. Capsaicin: A literature survey. Critical Reviews in Toxicology 10 (4):321-39. doi: 10.3109/10408448209003371.

Moon, Y. J., B. S. Shin, G. An, and M. E. Morris. 2008. Biochanin A inhibits breast cancer tumor growth in a murine xenograft model. Pharmaceutical Research 25 (9):2158-63. doi: 10.1007/s11095-0089583-6.

Mubarik, S., S. S. Malik, Z. Wang, C. Li, M. Fawad, and C. Yu. 2019. Recent insights into breast cancer incidence trends among four Asian countries using age-periodcohort model. Cancer Management and Research 11:8145-55. doi: 10.2147/CMAR.S208323.

Mubarik, S., F. Wang, M. Fawad, Y. Wang, I. Ahmad, and C. Yu. 2020. Trends and projections in breast cancer mortality among four asian countries (1990-2017). Scientific Reports 10 (1):1-12. doi: 10. 1038/s41598-020-62393-1.

Murakami, A., H. Ashida, and J. Terao. 2008. Multitargeted cancer pre- vention by quercetin. Cancer Letters 269 (2):315-25. doi: 10.1016/j. canlet.2008.03.046.

Nagle, D. G., D. Ferreira, and Y. D. Zhou. 2006. Epigallocatechin-3- gallate (EGCG): Chemical and biomedical perspectives. Phytochemistry 67 (17):1849-55. doi: $10.1016 /$ j.phytochem.2006.06. 020.

Nakagawa, H., K. Tsuta, K. Kiuchi, H. Senzaki, K. Tanaka, K. Hioki, and A. Tsubura. 2001. Growth inhibitory effects of diallyl disulfide on human breast cancer cell lines. Carcinogenesis 22 (6):891-7. doi: 10.1093/carcin/22.6.891.

Nakagawa, H., D. Yamamoto, Y. Kiyozuka, K. Tsuta, Y. Uemura, K. Hioki, Y. Tsutsui, and A. Tsubura. 2000. Effects of genistein and synergistic action in combination with eicosapentaenoic acid on the growth of breast cancer cell lines. Journal of Cancer Research and Clinical Oncology 126 (8):448-54. doi: 10.1007/PL00021280.

Nowacki, L., P. Vigneron, L. Rotellini, H. Cazzola, F. Merlier, E. Prost, R. Ralanairina, J. P. Gadonna, C. Rossi, and M. Vayssade. 2015. Betanin-enriched red beetroot (Beta vulgaris L.) extract induces apoptosis and autophagic cell death in MCF-7 cells. Phytotherapy Research: PTR 29 (12):1964-73. doi: 10.1002/ptr.5491.

Oh, S. M., Y. P. Kim, and K. H. Chung. 2006. Biphasic effects of kaempferol on the estrogenicity in human breast cancer cells. Archives of Pharmacal Research 29 (5):354-62. doi: $10.1007 /$ BF02968584.

Orhan, I., S. Nabavi, M. Daglia, G. Tenore, K. Mansouri, and S. Nabavi. 2015. Naringenin and atherosclerosis: A review of literature. Current Pharmaceutical Biotechnology 16 (3):245-51. doi: 10.2174/ 1389201015666141202110216.

Papadopoulos, V., A. Kapsis, H. Li, H. Amri, M. Hardwick, M. Culty, P. G. Kasprzyk, M. Carlson, J. P. Moreau, and K. Drieu. 2000. Drug-induced inhibition of the peripheral-type benzodiazepine receptor expression and cell proliferation in human breast cancer cells. Anticancer Research 20 (5A):2835-47.

Pardee, A., Y. Li, and C. Li. 2002. Cancer therapy with beta-lapachone. Current Cancer Drug Targets 2 (3):227-42. doi: 10.2174/ 1568009023333854.

Patel, P. B., and V. R. Thakkar. 2014. L-carvone induces P53, caspase 3 mediated apoptosis and inhibits the migration of breast cancer cell lines. Nutrition and Cancer 66 (3):453-62. doi: 10.1080/01635581. 2014.884230.

Patra, C. R., S. Mukherjee, and R. Kotcherlakota. 2014. Biosynthesized silver nanoparticles: A step forward for cancer theranostics? Nanomedicine (London, England) 9 (10):1445-8. doi: 10.2217/nnm. 14.89.

Pearce, A., M. Haas, R. Viney, S. A. Pearson, P. Haywood, C. Brown, and R. Ward. 2017. Incidence and severity of self-reported chemo- therapy side effects in routine 
care: A prospective cohort study. PLoS One 12 (10):e0184360. doi: 10.1371/journal.pone.0184360.

Peng, F., Q. Du, C. Peng, N. Wang, H. Tang, X. Xie, J. Shen, and J. Chen. 2015. A review: The pharmacology of isoliquiritigenin. Phytotherapy Research: PTR 29 (7):96977. doi: $10.1002 /$ ptr.5348.

Piattelli, M., L. Minale, and R. A. Nicolaus. 1965. Pigments of centro- spermae-V. Betaxanthins from Mirabilis jalapa L. Phytochemistry 4 (6):817-23. doi: $10.1016 /$ S0031-9422(00)86258-5.

Po, L. S., Z. Yu Chen, D. S. C. Tsang, and L. K. Leung. 2002. Baicalein and genistein display differential actions on estrogen receptor (ER) transactivation and apoptosis in MCF-7 cells. Cancer Letters 187 (1-2):33-40. doi: 10.1016/S0304-3835(02)00355-5.

Potze, L., F. B. Mullauer, S. Colak, J. H. Kessler, and J. P. Medema. 2014. Betulinic acid-induced mitochondria-dependent cell death is counterbalanced by an autophagic salvage response. Cell Death \& Disease 5 (4):e1169. doi: 10.1038/cddis.2014.139.

Preston, D. L., A. Mattsson, E. Holmberg, R. Shore, N. G. Hildreth, and J. D. Boice. 2002. Radiation effects on breast cancer risk: A pooled analysis of eight cohorts. Radiation Research 158 (2):220-35. doi: 10.1667/0033-7587(2002)158[0220:REOBCR]2.0.CO;2.

Ramachandran, C., S. Rodriguez, R. Ramachandran, P. K. R. Nair, H. Fonseca, Z. Khatib, E. Escalon, and S. J. Melnick. 2005. Expression profiles of apoptotic genes induced by curcumin in human breast cancer and mammary epithelial cell lines. Anticancer Research 25 (5):3293-302.

Ramljak, D., L. J. Romanczyk, L. J. Metheny-Barlow, N. Thompson, V. Knezevic, M. Galperin, A. Ramesh, and R. B. Dickson. 2005. Pentameric procyanidin from Theobroma cacao selectively inhibits growth of human breast cancer cells. Molecular Cancer Therapeutics 4 (4):537-46. doi: 10.1158/1535-7163.MCT-04-0286.

Rashid, M. U., A. Zaidi, D. Torres, F. Sultan, A. Benner, B. Naqvi, A. R. Shakoori, A. Seidel-Renkert, H. Farooq, S. Narod, et al. 2006. Prevalence of BRCA1 and BRCA2 mutations in Pakistani breast and ovarian cancer patients. International Journal of Cancer 119 (12): 2832-9. doi: 10.1002/ijc.22269.

Richards, K. L. 2019. The most powerful natural antioxidant discovered to date-hydroxytyrosol. ProHealth. https://www.prohealth.com/ library/the-mostpowerful-natural-antioxidant-discovered-to-date- hydroxytyrosol-29641.

Roohbakhsh, A., H. Parhiz, F. Soltani, R. Rezaee, and M. Iranshahi. 2014. Neuropharmacological properties and pharmacokinetics of the citrus flavonoids hesperidin and hesperetin: A mini-review. Life Sciences 113 (1-2):1-6. doi: 10.1016/j.lfs.2014.07.029.

Saarinen, N. M., A. W€arri, S. I. M€akel€a, C. Eckerman, M. Reunanen, Ahotupa, S. M. Salmi, A. A. Franke, L. Kangas, and R. Santti. 2000. Hydroxymatairesinol, a novel enterolactone precursor with antitumor properties from coniferous tree (Picea abies). Nutrition and Cancer 36 (2):207-16. doi: 10.1207/S15327914NC3602_10.

Sahelian, R. 2018. Phenolic compounds and acids: Benefit of phenols. http://www.raysahelian.com/phenolic.html.

Saleem, M. 2009. Lupeol, a novel anti-inflammatory and anti-cancer dietary triterpene. Cancer Letters 285 (2):109-15. doi: 10.1016/j.can- let.2009.04.033.

Salehi, B., A. Venditti, M. Sharifi-Rad, D. KrRegiel, J. Sharifi-Rad, A. Durazzo, M. Lucarini, A. Santini, E. Souto, E. Novellino, et al. 2019. The therapeutic potential of apigenin. International Journal of Molecular Sciences 20 (6):1305. doi: 10.3390/ijms20061305.

Sartippour, M. R., D. Heber, J. Ma, Q. Lu, V. L. Go, and M. Nguyen. 2001. Green tea and its catechins inhibit breast cancer xenografts. Nutrition and Cancer 40 (2):14956. doi: $10.1207 / \mathrm{S} 15327914 \mathrm{NC} 402$

Scheckel, K. A., S. C. Degner, and D. F. Romagnolo. 2008. Rosmarinic acid antagonizes activator protein-1-dependent activation of cycloox- ygenase-2 expression in human cancer and nonmalignant cell lines. The Journal of Nutrition 138 (11):2098-105. doi: 10.3945/jn.108. 090431.

Schirrmacher, V. 2019. From chemotherapy to biological therapy: A review of novel concepts to reduce the side effects of systemic can- cer treatment (review). International Journal of Oncology 54 (2): 407-19. doi: 10.3892/ijo.2018.4661.

Schudel, G. 1918. Ueber die Anthocyane von Beta vulgaris L. (var. rapacea Koch forma rubra L.) und Raphanus sativus L. (var. radicula pers.). doi: 10.3929/ethz-a000092375.

Seresht, H. R., B. J. Albadry, A. K. M. Al-Mosawi, O. Gholami, and H. Cheshomi. 2019. The cytotoxic effects of thymol as the major com- ponent of Trachyspermum ammi on breast cancer (MCF-7) cells. Pharmaceutical Chemistry Journal 53 (2):101-7. doi: 10.1007/s11094- 019-01961-w.

Shabbir, M. A., M. R. Khan, M. Saeed, I. Pasha, A. A. Khalil, and N. Siraj. 2017. Punicic acid: A striking health substance to combat metabolic syndromes in humans. Lipids in Health and Disease 16 (1):99. doi: 10.1186/s12944-017-0489-3.

Shang, D., Z. Li, Z. Zhu, H. Chen, L. Zhao, X. Wang, and Y. Chen. 2015. Baicalein suppresses 17-b-estradiol-induced migration, adhe- sion and invasion of breast cancer cells via the G protein-coupled receptor 30 signaling pathway. Oncology Reports 33 (4):2077-85. doi: 10.3892/or.2015.3786.

Shao, Z. M., Z. Z. Shen, C. H. Liu, M. R. Sartippour, V. L. Go, D. Heber, and M. Nguyen. 2002. Curcumin exerts multiple suppressive effects on human breast carcinoma cells. International Journal of Cancer 98 (2):234-40. doi: 10.1002/ijc.10183.

Shareef, M., M. A. Ashraf, and M. Sarfraz. 2016. Natural cures for breast cancer treatment. Saudi Pharmaceutical Journal: SPJ 24 (3): 233-40. doi: 10.1016/j.jsps.2016.04.018.

Sharma, G. N., R. Dave, J. Sanadya, P. Sharma, and K. K. Sharma. 2010. Various types and management of breast cancer: An overview. Journal of Advanced Pharmaceutical Technology \& Research 1 (2): 109-26.

Shukla, S., and S. Gupta. 2010. Apigenin: A promising molecule for cancer prevention. Pharmaceutical Research 27 (6):962-78. doi: 10. 1007/s11095-010-0089-7.

Siegel, R., J. Ma, Z. Zou, and A. Jemal. 2014. Cancer statistics, 2014. CA: A Cancer Journal for Clinicians 64 (1):9-29. doi: 10.3322/caac. 21208.

Siegel, R., D. Naishadham, and A. Jemal. 2012. Cancer statistics, 2012. CA: A Cancer Journal for Clinicians 62 (1):10-29. doi: 10.3322/caac. 20138.

Sigounas, G., J. Hooker, A. Anagnostou, and M. Steiner. 1997. S-allyl- mercaptocysteine inhibits cell proliferation and reduces the viability of erythroleukemia, breast, and prostate cancer cell lines. Nutrition and Cancer 27 (2):186-91. doi: 10.1080/01635589709514523.

Simmler, C., G. F. Pauli, and S. N. Chen. 2013. Phytochemistry and biological properties of glabridin. Fitoterapia 90:160-84. doi: 10. 1016/j.fitote.2013.07.003.

Singh, S., B. Sharma, S. S. Kanwar, and A. Kumar. 2016. Lead phyto- chemicals for anticancer drug development. Frontiers in Plant Science 7:1667. doi: 10.3389 /fpls.2016.01667.

Singletary, K. W., and S. M. Gapstur. 2001. Alcohol and breast cancer: Review of epidemiologic and experimental evidence and potential mechanisms. JAMA 286 (17):2143-51. doi: 10.1001/jama.286.17. 2143.

So, F. V., N. Guthrie, A. F. Chambers, M. Moussa, and K. K. Carroll. 1996. Inhibition of human breast cancer cell proliferation and delay of mammary tumorigenesis by flavonoids and citrus juices. Nutrition and Cancer 26 (2):167-81. doi: 10.1080/ 01635589609514473.

Sucha, L., M. Hroch, M. Rezacova, E. Rudolf, R. Havelek, L. Sispera, J. Cmielova, R. Kohlerova, A. Bezrouk, and P. Tomsik. 2013. The cyto- toxic effect of a-tomatine in MCF-7 human adenocarcinoma breast cancer cells depends on its interaction with cholesterol in incubation media and does not involve apoptosis induction. Oncology Reports 30 (6):2593-602. doi: 10.3892/or.2013.2778.

Sun, J. 2007. D-limonene: Safety and clinical applications. Alternative Medicine Review 12 (3):259-64. Sun, Y. S., Z. Zhao, Z. N. Yang, F. Xu, H. J. Lu, Z. Y. Zhu, W. Shi, J. Jiang, P. P. Yao, and H. P. Zhu. 2017. Risk factors and preventions of breast cancer. International Journal of Biological Sciences 13 (11): 1387-97. doi: 10.7150/ijbs.21635.

Suresh, C., H. Zhao, A. Gumbs, C. S. Chetty, and H. S. Bose. 2012. New ionic derivatives of betulinic acid as highly potent anti-cancer agents. Bioorganic \& Medicinal Chemistry Letters 22 (4):1734-8. doi: 10.1016/j.bmcl.2011.12.102.

Takaoka, M. 1940. Of the phenolic substrate of hellebore (Veratrum grandiflorum Loes. fil.). Journal of the Faculty of Science, Hokkaido Imperial University 3:1-16. Tamir, S., M. Eizenberg, D. Somjen, N. Stern, R. Shelach, A. Kaye, and J. Vaya. 2000. Estrogenic and antiproliferative properties of glabridin from licorice in human breast cancer cells. Cancer Research 60 (20): 5704-9.

Tariq, A., S. Sadia, K. Pan, I. Ullah, S. Mussarat, F. Sun, O. O. Abiodun, A. Batbaatar, Z. Li, D. Song, et al. 2017. A systematic review on ethnomedicines of anti-cancer plants. Phytotherapy Research: PTR 31 (2):202-64. doi: 10.1002/ptr.5751.

Tesoriere, L., M. Allegra, C. Gentile, and M. A. Livrea. 2009. Betacyanins as phenol antioxidants. chemistry and mechanistic aspects of the lipoperoxyl radicalscavenging activity in solution and liposomes. Free Radical Research 43 (8):706-17. doi: 10.1080/ 10715760903037681.

Thoennissen, N. H., J. O'Kelly, D. Lu, G. B. Iwanski, D. T. La, S. Abbassi, A. Leiter, B. Karlan, R. Mehta, and H. P. Koeffler. 2010. Capsaicin causes cell-cycle arrest and apoptosis in ER-positive and-negative breast cancer cells by modulating the EGFR/HER-2 path- way. Oncogene 29 (2):285-96. doi: 10.1038/onc.2009.335.

Tidgewell, K., B. R. Clark, and W. H. Gerwick. 2010. The natural prod- ucts chemistry of cyanobacteria. In Comprehensive natural products II: Chemistry and biology, vol. 2, 141-88. Amsterdam, the Netherlands: Elsevier Ltd. doi: 10.1016/B978-008045382-8.00041-1.

Tiwari, B., N. Brunton, and C. Brennan. 2013. Handbook of plant food phytochemicals: sources, stability and extraction. Hoboken, NJ: Wiley-Blackwell.

Tiwari, R. K., L. Guo, H. L. Bradlow, N. T. Telang, and M. P. Osborne. 1994. Selective responsiveness of human breast cancer cells to indole-3-carbinol, a chemopreventive agent. Journal of the National Cancer Institute 86 (2):126-31. doi: 10.1093/jnci/86.2.126.

Tour' e, A., and X. Xueming. 2010. Flaxseed lignans: Source, biosyn- thesis, metabolism, antioxidant activity, bio-active components, and health benefits. 
Comprehensive Reviews in Food Science and Food Safety 9 (3):261-9. doi: 10.1111/j.1541-4337.2009.00105.x.

Travis, L. B., D. A. Hill, G. M. Dores, M. Gospodarowicz, F. E. van Leeuwen, E. Holowaty, B. Glimelius, M. Andersson, T. Wiklund, C. F. Lynch, et al. 2003. Breast cancer following radiotherapy and chemotherapy among young women with Hodgkin disease. JAMA 290 (4):465-75. doi: 10.1001/jama.290.4.465.

Tremblay, A., H. Arguin, and S. Panahi. 2016. Capsaicinoids: A spicy solution to the management of obesity. International Journal of Obesity (2005) 40 (8):1198-204. doi: 10.1038/ijo.2015.253.Upadhyay, R. K. 2018. Plant pigments as dietary anticancer agents. International Journal of Green Pharmacy 12 (1):S93.

Vel Szic, K. S., K. Declerck, R. A. J. Crans, J. Diddens, D. B. Scherf, C. Gerh€auser, and W. Vanden Berghe. 2017. Epigenetic silencing of tri- ple negative breast cancer hallmarks by withaferin A. Oncotarget 8 (25):40434-53. doi: 10.18632/oncotarget.17107.

Vigushin, D. M., G. K. Poon, A. Boddy, J. English, G. W. Halbert, C. Pagonis, M. Jarman, and R. C. Coombes. 1998. Phase I and pharma- cokinetic study of D-limonene in patients with advanced cancer. Cancer Research Campaign Phase I/II Clinical Trials Committee. Cancer Chemotherapy and Pharmacology 42 (2):111-7. doi: $10.1007 / \mathrm{s} 002800050793$.

Vilaplana-P' erez, C., D. Aun o' n, L. A. Garc' 1a-Flores, and A. Gil- Izquierdo. 2014. Hydroxytyrosol and potential uses in cardiovascular diseases, cancer, and AIDS. Frontiers in Nutrition 1:1-11. doi: 10. 3389/fnut.2014.00018.

Vinogradov, S., and X. Wei. 2012. Cancer stem cells and drug resist- ance: The potential of nanomedicine. Nanomedicine (London, England) 7 (4):597-615. doi: $10.2217 / \mathrm{nnm} .12 .22$

Wakimoto, N., D. Yin, J. O’Kelly, T. Haritunians, B. Karlan, J. Said, H. Xing, and H. P. Koeffler. 2008. Cucurbitacin B has a potent antipro- liferative effect on breast cancer cells in vitro and in vivo. Cancer Science 99 (9):1793-7. doi: 10.1111/j.1349-7006.2008.00899.x.

Wang, H., T. Oo Khor, L. Shu, Z. Y. Su, F. Fuentes, J. H. Lee, and N. Tony Kong. 2012. Plants vs. cancer: A review on natural phy- tochemicals in preventing and treating cancers and their druggabil- ity. Anti-Cancer Agents in Medicinal Chemistry 12 (10):1281-305. doi: 10.2174/187152012803833026.

Wang, N., Z. Wang, Y. Wang, X. Xie, J. Shen, C. Peng, J. You, F. Peng, H. Tang, X. Guan, et al. 2015. Dietary compound isoliquiriti- genin prevents mammary carcinogenesis by inhibiting breast cancer stem cells through WIF1 demethylation. Oncotarget 6 (12):9854-76. doi: 10.18632/oncotarget.3396.

Wang, N., Z. Y. Wang, S. L. Mo, T. Y. Loo, D. M. Wang, H. Bin Luo, D. P. Yang, Y. L. Chen, J. G. Shen, and J. P. Chen. 2012. Ellagic acid, a phenolic compound, exerts anti-angiogenesis effects via VEGFR-2 signaling pathway in breast cancer. Breast Cancer Research and Treatment 134 (3):943-55. doi: 10.1007/s10549-0121977-9.

Wang, Y., K. W. Lee, F. L. Chan, S. Chen, and L. K. Leung. 2006. The red wine polyphenol resveratrol displays bilevel inhibition on aro- matase in breast cancer cells. Toxicological Sciences 92 (1):71-7. doi: 10.1093/toxsci/kfj190.

Watabe, M., K. Hishikawa, A. Takayanagi, N. Shimizu, and T. Nakaki. 2004. Caffeic acid phenethyl ester induces apoptosis by inhibition of NFkappaB and activation of Fas in human breast cancer MCF-7 cells. The Journal of Biological Chemistry 279 (7):6017-26. doi: 10. 1074/jbc.M306040200.

Weng, J. R., C. H. Tsai, S. K. Kulp, and C. S. Chen. 2008. Indole-3-car- binol as a chemopreventive and anti-cancer agent. Cancer Letters 262 (2):153-63. doi: 10.1016/j.canlet.2008.01.033.

Yao, Y., and Q. Zhou. 2010. A novel antiestrogen agent shikonin inhib- its estrogen-dependent gene transcription in human breast cancer cells. Breast Cancer Research and Treatment 121 (1):233-40. doi: 10. 1007/s10549-009-0547-2.

Yesil-Celiktas, O., C. Sevimli, E. Bedir, and F. Vardar-Sukan. 2010. Inhibitory effects of rosemary extracts, carnosic acid and rosmarinic acid on the growth of various human cancer cell lines. Plant Foods for Human Nutrition (Dordrecht, Netherlands) 65 (2):158-63. doi: 10.1007/s11130-010-0166-4.

Yi, L. V., S. O. Kwok Fai, W. N. Kei, and X. Jia. 2019. Anti-cancer activities of S-allylmercaptocysteine from aged garlic. Chinese Journal of Natural Medicines 17 (1):439. doi: 10.1016/S1875- 5364(19)30008-1.

Yiannakopoulou, E. C. 2014. Effect of green tea catechins on breast carcinogenesis: A systematic review of in-vitro and in-vivo experi- mental studies. European Journal of Cancer Prevention 23 (2):84-9. doi: 10.1097/CEJ.0b013e328364f23e.

Yin, F., A. E. Giuliano, R. E. Law, and A. J. Van Herle. 2001. Apigenin inhibits growth and induces G2/M arrest by modulating cyclin-CDK regulators and ERK MAP kinase activation in breast carcinoma cells. Anticancer Research $21(1 \mathrm{~A}): 413-20$.

Yoder, S. C., S. M. Lancaster, M. A. J. Hullar, and J. W. Lampe. 2015. Gut microbial metabolism of plant lignans: Influence on human health. In Diet-microbe interactions in the gut: Effects on human health and disease, 103-17. Cambridge, MA: Academic Press. doi: 10.1016/B978-0-12-407825-3.00007-1.

Yokota, T., Y. Matsuzaki, M. Koyama, T. Hitomi, M. Kawanaka, M. Enoki-Konishi, Y. Okuyama, J. Takayasu, H. Nishino, A. Nishikawa, et al. 2007. Sesamin, a lignan of sesame, down-regulates cyclin D1 protein expression in human tumor cells. Cancer Science 98 (9): 1447-53. doi: 10.1111/j.1349-7006.2007.00560.x.

Yoon, Y., J. Hwang, M. Sung, S. Wang, and J. Park. 2012. Inhibitory effect of biochanin a on CAMP level in HEK293 cells. Planta Medica 78 (11):PI455. doi: $10.1055 / \mathrm{s}-0032-1321142$.

Youn, H. J., and W. Han. 2020. A review of the epidemiology of breast cancer in Asia: Focus on risk factors. Asian Pacific Journal of Cancer Prevention: APJCP 21 (4):867-80. doi: 10.31557/APICP.2020.21.4.867.

Yu, J., X. Bi, B. Yu, and D. Chen. 2016. Isoflavones: Anti-inflammatory benefit and possible caveats. Nutrients 8 (6):361. doi: $10.3390 /$ nu8060361.

Yu, Y., Q. Zhou, Y. Hang, X. Bu, and W. Jia. 2007. Antiestrogenic effect of 20S-protopanaxadiol and its synergy with tamoxifen on breast cancer cells. Cancer 109 (11):2374-82. doi: $10.1002 /$ cncr. 22659.

Zanwar, A. A., S. L. Badole, P. S. Shende, M. V. Hegde, and S. L. Bodhankar. 2013. Antioxidant role of catechin in health and disease. In Polyphenols in human health and disease, vol. 1, 267-71. Cambridge, MA: Academic Press. doi: 10.1016/B978-0-12-398456-2. 00021-9.

Zhang, G., Y. Wang, Y. Zhang, X. Wan, J. Li, K. Liu, F. Wang, K. Liu, Q. Liu, C. Yang, et al. 2012. Anti-cancer activities of tea epigalloca- techin-3-gallate in breast cancer patients under radiotherapy. Current Molecular Medicine 12 (2):163-76. doi: 10.2174/ 156652412798889063.

Zhang, H., H. L. Xu, Y. C. Wang, Z. Y. Lu, X. F. Yu, and D. Y. Sui. 2018. 20(S)-protopanaxadiol-induced apoptosis in MCF-7 breast cancer cell line through the inhibition of PI3K/AKT/MTOR signal- ing pathway. International Journal of Molecular Sciences 19 (4):1053. doi: 10.3390/ijms19041053.

Zhang, L., Y. K. Lau, W. Xia, G. N. Hortobagyi, and M. C. Hung. 1999. Tyrosine kinase inhibitor emodin suppresses growth of HER- 2/Neu-overexpressing breast cancer cells in athymic mice and sensi- tizes these cells to the inhibitory effect of paclitaxel 1. Clinical Cancer Research 5 (2):343-53.

Zhang, Y., S. K. Vareed, and M. G. Nair. 2005. Human tumor cell growth inhibition by nontoxic anthocyanidins, the pigments in fruits and vegetables. Life Sciences 76 (13):1465-72. doi: 10.1016/j.lfs.2004. 08.025.

Zheng, N., P. Zhang, H. Huang, W. Liu, T. Hayashi, L. Zang, Y. Zhang, L. Liu, M. Xia, S-i Tashiro, et al. 2015. ERa down-regulation plays a key role in silibinininduced autophagy and apoptosis in human breast cancer MCF-7 cells. Journal of Pharmacological Sciences 128 (3):97-107. doi: 10.1016/i.jphs.2015.05.001.

Zheng, Y., P. Liu, N. Wang, S. Wang, B. Yang, M. Li, J. Chen, H. Situ, M. Xie, Y. Lin, et al. 2019. Betulinic acid suppresses breast cancer metastasis by targeting GRP78-mediated glycolysis and ER stress apoptotic pathway. Oxidative Medicine and Cellular Longevity 2019: 8781690-15. doi: 10.1155/2019/8781690. 